\title{
Containing Conflict? The Effect of the Intermodal Transport Revolution
}

\begin{abstract}
August, 2020
Abstract

How does trade affect the likelihood of conflict? This enduring question unifies the two major subfields of international relations. Yet despite extensive scholarship, there remains a lack of consensus. Inference has been handicapped by the reciprocal nature of trade and conflict. To address this difficulty, this paper studies the trade and conflict nexus in the wake of an important technological change - the introduction of shipping containers. It offers two main contributions. First, it uses the exogenous technological shock of containerization to identify the effect of trade on conflict. Perhaps surprisingly, trade gains induced by containerization substantially increase the incidence of conflict within country pairs. Second, it develops a new theoretical model to explain these novel findings. Bargaining breakdowns are exacerbated when the exact benefits of trade are uncertain and one side suspects the other's gains are large relative to their own. This informational environment closely parallels the context of a technological shock.
\end{abstract}

\section{9,489 words}




\section{Introduction}

How does trade affect the likelihood of conflict? Extensive research has yielded opposing conclusions. On the one hand, a venerable tradition in international relations holds that economic integration tempers conflict (Benthem, 1789; Kant, 1795). In the 1990s, these theories experienced a renaissance as "the liberal peace" (Doyle, 1983; Copeland, 1996; Oneal et al., 1996; Oneal and Russett, 1999). Liberals argue that trade creates mutual benefits which make ties costly to sever. Conflict disrupts these benefits, so incentives to fight recede as trade increases. In modern economic parlance, trade raises the opportunity cost of strife. More recent scholarship incorporates the opportunity cost mechanism into formal treatments of conflict (Crescenzi, 2003; Martin, Mayer and Thoenig, 2008; Polachek and Xiang, 2010).

On the other hand, the liberal hypothesis and the opportunity cost mechanism have engendered considerable debate. Realists argue that trade makes war more likely by creating vulnerabilities and imbalances of power. For realists, opportunity cost considerations are dominated by concerns over relative gains (Grieco, 1988; Grieco, Powell and Snidal, 1993; Mastanduno, 1991). Moreover, fighting is already a costly enterprise and the portion of trade forfeit in a contest is often modest in scale (Gartzke and Zhang, 2015). Additionally, increasing an actor's cost of conflict only enhances the appeal of behaving aggressively toward that actor. Lastly, different regime types may internalize the benefits of trade differently or not at all (Gelpi and Grieco, 2003; McDonald, 2004; Gelpi and Grieco, 2008).

Existing evidence for and against these positions faces important limits to drawing causal inferences. In a review of existing empirical evidence relating trade and 
conflict Gartzke and Zhang (2015) conclude, "While a robust correlation exists between dyadic trade and interstate disputes, it is difficult to determine causality. It is plausible that trade reduces war as the liberals claim, but it is equally likely that peace leads to an increase in trade."

This paper studies the post-World War II international trade boom and demonstrates that trade increases conflict - contrary to the plurality of existing empirical assessments - by examining the sudden jump in trade that occurs when a pair of states adopt shipping container technology. This cost-shifting technological shock has not received attention from either proponents or opponents of the liberal peace, but provides a crucial opportunity to assess one of the most widely debated theories in international relations. Studying trade and conflict in the context of the intermodal transportation revolution enables two main contributions. First, it facilitates a strong research design. Second, it prompts the theoretical question of how a rapid, unforeseen trade boost differs from the slow, gradual growth of a trading relationship.

Container technology sharply expanded global trade by dramatically lowering the cost of shipping. However, both members of a trading pair needed container facilities in order to reap the benefits. This requirement generates substantial cross-sectional and inter-temporal variation in the adoption of shipping containers among country dyads. This variation enables an instrumental variable identification strategy. The results compare the differences in conflict within dyads before and after containerization, scaling the effect of containerization on conflict by containerization's effect on trade.

Contrary to the preponderance of existing analyses, I find that trade growth in- 
duced by containerization increases the incidence of conflict. The main outcome of interest is a count variable equal to the number of militarized interstate disputes (MIDs) between a pair of countries during a calendar year. The instrumental variables estimates identify a large, positive, and statistically significant effect of trade on the incidence of interstate conflict. Hypothetically increasing trade by 10 percent increases the expected number of conflicts by about .0015. Given that the baseline rate of conflicts per dyad-year is 0.0035 , this effect is sizable.

These results are at odds with the liberal peace and its accompanying opportunity cost mechanism, but contrary theories do not explicitly articulate the mechanisms through which trade increases conflict. I show formally that if each party's precise trade benefits are private information then trade can increase the incidence of conflict. This setup closely parallels the context of a technological shock, such as containerization. Interested parties can realize that an invention is unequivocally beneficial, but the exact extent of the benefits may not be known at the outset (e.g. the invention of the internet, the dotcom bubble, its subsequent bust, and the recent reascendance of the tech sector). There is also no reason to expect different parties to obtain the same benefit (e.g. the internet revolutionized financial services, but had a limited impact on the mining industry).

Despite unquestionably raising the opportunity cost of conflict, technological shocks such as containerization also heighten the uncertainty surrounding those costs - which is among the most popular mechanisms that explain conflict. The latter effect can dominate in equilibrium, meaning that the probability of a breakdown increases despite the increased opportunity costs. The model builds on the 
intuition of screening. When bargaining, a demander that is uninformed of its opponent's breakdown cost faces a fundamental trade-off. On the one hand, the demander can propose a generous settlement that both low-cost and high-cost opponents would accept. This has the benefit of avoiding a costly conflict. Alternatively, the demander can issue an aggressive demand and screen the opponent's willingness to fight. In this scenario, high-cost opponents accept while low-cost opponents reject. This leaves the demander with a larger share of the resource in the event of acceptance, but also requires the demander to pay the cost of conflict in the event of rejection.

Within this framework, shipping container technology impacts the demander's calculus in two opposing ways. First, a demander's incentive to screen falls as their own internalized trade benefit grows. Screening forces the proposer to risk a conflict, in the event of which this newfound benefit is lost. On the other hand, the opponent may be benefiting disproportionately from the new technology. The more the demander believes its opponent is benefitting, the more attractive it is for the demander to issue a larger ultimatum demand. This increased incentive to screen can outweigh the increased opportunity cost of conflict. When the demander believes the opponent's likely trade benefits surpass their own by beyond a certain margin, they make more aggressive demands that carry a greater risk of rejection relative to the pre-shock world.

Taken in concert, these empirical and theoretical findings augment how scholars traditionally believe economic interdependence mediates conflict. They highlight circumstances under which skeptics of the opportunity cost mechanism are correct. The increased likelihood of conflict does not stem from asymmetric gains per se, but 
rather the possibility of asymmetric gains. Relative gains are not, as the realists claimed, always a driving force of conflict nor are they universally irrelevant.

\section{Theory and Evidence}

The lion's share of empirical work finds a negative correlation between trade and conflict, and the prevailing theoretical view is that burgeoning trade tempers the likelihood of conflict by increasing opportunity costs. This section begins by briefly summarizing the existing empirical work on trade and conflict and highlighting the key differences in this paper's research design. The most notable difference is that this paper leverages a technological shock for identification. Section 2.2 summarizes the key assumptions about costs, benefits, and information in opportunity cost based theories. It then outlines existing theoretical pathways which circumvent or reject the opportunity cost mechanism. Lastly, it introduces asymmetric information as an explanation of how trade increases conflict.

\section{$2.1 \quad$ Evidence}

The plurality of empirical work finds a negative correlation between trade and hostilities (Polachek, 1980; Mansfield, 1994; Oneal et al., 1996; Oneal and Russett, 1999). However, a substantial number of studies report null (Li and Reuveny, 2011; Ward, Sieverson and Xun, 2007; Gartzke, Li and Boehmer, 2001; Gartzke and Li, 2003) or even contradictory results (Barbieri, 1996, 2002). What explains this discrepancy? Much of the empirical literature relies on cross-national time series data and does 
not effectively deal with endogeneities between trade and conflict. A particularly well known critique is that the existing literature is unable to adequately address the possibility of reverse causality. Simply put, it is difficult to determine whether trade fosters peace or peace fosters trade using extant observational data. Blainey (1988) was the first to make this point, arguing that peace creates the conditions for interdependence and not the reverse. Pollins (1989) argued trade "follows the flag," meaning that international politics affects trade but not vice-versa. ${ }^{1}$ Indeed, if forward-looking economic actors account for the possibility of future political disruptions when deciding with whom to trade then the realization of an international incident will necessarily be correlated with lower trade (Morrow, 1999; Benson and Niou, 2010).

While the reciprocal relationship between trade and conflict has long been acknowledged, most empirical research has focused on one direction or the other. A very small set of previous work models trade and conflict simultaneously. The main difference between my application and earlier efforts is the inclusion of an exogenous technological shock: the container revolution. Previous results were highly dependent on model specification and the particular parameters excluded from each equation in the system, such as distance or population. Kim (1998) was the first to model trade and conflict simultaneously, reporting null results for both directions. Keshk, Pollins, and Reuveny (2004) readdressed the topic with a more gravity-like trade specification and found that interstate disputes reduce bilateral trade, but trade does not reduce the risk of a dispute. ${ }^{2}$ On the other hand Hegre, Oneal, and Russett (2010)

\footnotetext{
${ }^{1}$ See also Gowa and Mansfield (1993) and Gowa (1994).

${ }^{2}$ See also Kim and Rousseau (2005)
} 
and Goenner (2011) obtained opposite results by simply switching some of included and excluded parameters in each equation. To the best of my knowledge, these five papers comprise the universe of studies which seek to account for reverse causality in the trade and conflict relationship.

\subsection{Theory}

The liberal peace originated in the 16th century writings of Benthem, Cobden, and Kant. These authors explain proclivity toward war as a function of the responsiveness of governments to societal interests. However, republican government alone is not a sufficent condition for peaceful international relations (Doyle, 1983). International traders appeal to leaders to refrain from conflict, which is bad for business (Oneal and Russett, 1999). Leaders must placate trading classes or risk losing office, making

the logic implicitly similar to selectorate theory (Mesquita et al., 2003). In Kant's view, pacification may be amplified in regime types that are more responsive to civil society, such as democracies.

Polachek and Xiang (2010) formalize this logic with a straightforward bargaining model. In their baseline model without trade, contestant's costs of fighting are private information while the probability that a given contestant wins is common knowledge. In this setup, the equilibrium demand and the rate of bargaining breakdown are both decreasing functions of the demander's costs. Since the probability of rejection is solely an increasing function of demand size, higher cost demanders prefer to make lower demands and pay the costs of fighting less frequently.

Adding commonly known trade benefits to the baseline model always reduces 
the chances of a bargaining breakdown. The key is that trade benefits are common knowledge. This means adding all of the benefits to any demand from the no-trade model has no effect on the breakdown rate. However, in a breakdown the demander now loses these trade benefits in addition to paying the costs of fighting. These foregone benefits are essentially increased costs for the demander, which further suppress demands and the breakdown rate.

However, there are alternative theories which draw more nuanced conclusions. The premise of these theories is that trade's effect on peace will vary depending on how trade benefits are distributed within a society. MacDonald (2004) argued that peace might not be caused by increasing trade volumes but rather by changes to the domestic mix of relative winners and losers brought about by specific trade policies. If trade expands because of policy liberalization then pro-trade groups, such as citizen consumers, are more influential in limiting aggressive foreign policies vis-a-vis groups that traditionally benefit from aggressive foreign and autarkic trade policies, such as import-competing domestic firms. Thus liberalization, not trade per se, causes less conflict. If on the other hand trade volume expands as a consequence of technological innovations, such as shipping containers, it will not yield more peace.

Gelpi and Greico $(2003 ; 2008)$ theorize a similarly nuanced effect of trade on conflict. Since trade can help promote economic growth, and growth is important to voters, office-motivated democratic leaders face electoral costs if conflict halts trade. This implies that democracies are less likely to enter into conflict with trading partners. They posit no relationship at all for autocracies, wherein leaders do not face electoral challenges. Papayoanou (1996) and Solingen (2003) provide additional 
evidence for this argument with case studies.

The key insight of these alternative theories, that rising trade creates distinct domestic benefits that differ by country, explains how more trade causes more conflict. These benefits are the result of complex political machinations and can be difficult for opponents to know with certainty, especially during times of rapid technological disruption. To account for this uncertainty, I extend Polacheck and Xiang's model to incorporate trade benefits which are strictly positive but not precisely known. When the benefits of trade are common knowledge, more trade unambiguously reduces the incidence of fighting. This is not the case when trade benefits are modeled as additional asymmetric information. The probability of a bargaining breakdown in the post trade world can exceed that of the pre-trade world. This occurs when the demander suspects that their opponent's trade benefits may surpass theirs by more than a certain amount. The intuition is that the demander has relatively less to lose, and potentially more to gain, from making a larger demand even if it is rejected more frequently. This helps explain the destabilizing effect of trade uncovered in the empirical results.

This model also contributes to recent literature that applies the rationalist framework (Fearon, 1995) to explain how trade might increase conflict. Copeland (2015) theorizes that the expected value of future trade plays an important role. This expected value can be negative if there is a high cost of despecialization, such as rebuilding defunct domestic industries, in the event trade is cut off. Since readjustment costs drag on the domestic economy and in turn military power, a state that becomes too dependent on a trading partner will prefer to preemptively attack. Rather than 
focus on commitment problems, I address the informational environment. In this domain, my model is closest to Spaniel and Malone's (2019). They assume perfect information about conflict costs and trade benefits but allow for asymmetric information regarding each player's valuation of the contested resource, uncovering a nonmonotonic relationship between trade benefits and bargaining breakdowns. The advantage of my setup, in which information asymmetries are in regard to trade itself, is that it closely parallels the empirical context of a technological shock.

\section{The Container Revolution}

This section gives a brief history of the aspects of containerization relevant to this study. First, it provides historical evidence that containerization lowered the cost of trade. Second, it shows that both importing and exporting ports needed considerable modification before the benefits of containerization could be realized. This makes the variation in trade dyadic as opposed to unilateral, which provides useful variation. Third, it offers evidence that containerization quickly penetrated the domestic transportation networks of participant countries. Such rapid adoption supports treating containerization as a shock.

Trade has crossed political boundaries since antiquity. The earliest evidence of international trade are records of an Assyrian merchant colony established 4,000 years ago in present-day Turkey. These traders moved goods with roughly the same methods employed at turn of the 20th century. Ships were hand loaded and unloaded with boxes, barrels, sacks, and crates. Workers carried individual items below deck, 
maneuvered them through confined spaces, and packed them into tight quarters. The whole endeavor was extremely slow and labor intensive. So much so that ships commonly spent twice as long in port as they did at sea (World Shipping Council 2019). Moreover, this process was repeated numerous times as goods reached new transportation junctions. Such repetition intensified the risk of accident and loss, particularly due to theft. New York's dockworkers were said to earn "twenty dollars a day and all the scotch you could carry home," (Frey 2019). This arduous process, called break-bulk shipping, was the only available means of cargo packing prior to the invention of shipping containers. As railroads and steam ships increased the velocity of trade in the 19th century, transferring cargo between carriers became the obvious long pole in the tent of globalization.

In 1956 Malcom McLean, a North Carolina trucking proprietor, introduced a major advance (Levinson 2006). McLean retrofitted an oil tanker, the Ideal-X, with wooden decking and stacked fifty-eight fully loaded trailer wagons on top of it. The trailers, which came to be known as containers, were loaded only once at the production site and then placed directly onto the ship. Trailers were similarly offloaded and immediately dispatched via trucks waiting at the destination port.

Even in this nascent stage, the channel through which containerization would increase trade was already apparent: bypassing labor. McLean's records show that it cost $\$ 0.16$ per ton to load containers compared with $\$ 5.83$ per ton for loose cargo. An official of the International Longshoreman's Association commented on the Ideal-X, "I'd like to sink that son of a bitch." The first ship specifically designed to transport containers, the Gateway City, sailed soon after in 1957. Gateway City on- 
boarded 264 tons of cargo per hour as opposed to the 10 tons per hour loaded by a stevedoring crew. Moreover, since containers are carried by multiple modes of transportation - ships, trains, and trucks - they eliminated as many as 12 separate handlings (Containerization International 1970). Packing and sealing containers at the factory also sharply curtailed theft. This in turn drastically reduced insurance costs. Paul Krugman (2009) summarized the impending transformation as follows:

The ability to ship things long distances fairly cheaply has been there since the steamship and the railroad. What was the big bottleneck was getting things on and off the ships. A large part of the costs of international trade was taking the cargo off the ship, sorting it out, and dealing with the pilferage that always took place along the way. So, the first big thing that changed was the introduction of the container. When we think about technology that changed the world, we think about glamorous things like the internet. But if you try to figure out what happened to world trade, there is a really strong case to be made that it was the container, which could be hauled off a ship and put onto a truck or a train and moved on. It used to be the case that ports were places with thousands and thousands of longshoremen milling around loading and unloading ships. Now longshoremen are like something out of those science fiction movies in which people have disappeared and been replaced by machines.

However, containerization entailed much more than simply packing goods into boxes. Both importing and exporting ports required comprehensive modification before the benefits of containerization could be realized. A port cannot handle 
containers without specific cranes, storage facilities, and rail terminals. The first purpose-built cranes, capable of loading 400 tons per hour, were introduced in 1959 (Levinson, 2006). This throughput made larger ships, introduced soon after, economically viable. Larger cranes and ships necessitated complementary changes in storage and trucking facilities. Recognizing the global potential of container shipping, the International Organization for Standardization homogenized container sizes in 1961. Standardization allowed containers to move between different companies' ships and to easily cross international boundaries.

These mechanical requirements and international standards where already in place before containerization began to spread internationally. In 1966, oversea service commenced between Germany, Holland, the United Kingdom, and the United States. Overland rail service followed in 1967 when a consortium of European railroads formed Intercontainer (Bernhofen, El-Sahli and Kneller, 2016). Rail containerization enabled landlocked countries like Austria and Switzerland to participate in intermodalism. While most coastwise countries first containerized by seaport, this was not always the case. For example, Norway began shipping containers by rail in 1969 and did not make a sea shipment until 1974. This shows that countries could containerize by rail or by sea. Between 1966 and 1983 containerization spread to 122 countries. No further countries adopted the technology until after the 1990s, by which time the next shipping revolution, air transport, was incipient. For these reasons, the 1966-1983 period is considered the golden age of containerization.

Bernhofen, El-Sahli and Kneller (2016) provide evidence that containerization quickly propagated through the domestic transportation network of constituent economies. 
To measure this diffusion, they construct a container utilization index equal to an economy's containerized trade volume divided by its total trade in containerizable cargo. The notion of containerizability accounts for the fact that some tradable goods, for example heavy equipment and fully assembled automobiles, cannot be put into containers. Since there are no records of container trade via rail and truck, they focus on two island economies where international trade must have passed through seaports: the United Kingdom and Japan. Specifically, they obtain the annual gross tonnage of container trade processed at seaports, announced in Containerisation International, and divide it by the total gross tonnage of trade in containerizable products taken from OECD International Trade by Commodity Statistics. Within three years of constructing container facilities, $50 \%$ of all potentially containerizable trade in the UK was already containerized. Japan reached the $50 \%$ threshold in four years.

\section{Empirical Design}

The empirical strategy compares the occurrence of militarized interstate disputes (MIDs) within pairs of countries, using the fact that countries containerized at different times to form comparison groups. ${ }^{3}$ The estimates scale containerization's effect on conflict by its effect on trade. In this application containerization functions as an instrument in the classic economic sense. Containerization shifts the trade equation by lowering transportation costs, tracing out the conflict equation. In doing so, it makes it possible to estimate the parameters of the conflict equation. This section

\footnotetext{
${ }^{3}$ Section 5 provides a detailed description of MID data.
} 
begins by outlining the trade and conflict system to be estimated. It then details the identification strategy, including threats to identification and suitable countermeasures. Lastly, it briefly discusses estimation practicalities.

To help understand the variation driving the results, consider the trade and conflict system where containerization instruments trade:

$$
\begin{gathered}
{[\text { Trade }]_{i j t}=\alpha[\text { Both Containerized }]_{i j t}+\boldsymbol{X}_{i j t} \Gamma+\vartheta_{t}+\psi_{i j}+\epsilon_{i j t}} \\
{[\mathrm{MIDs}]_{i j t}=\beta[\text { Trade }]_{i j t}+\boldsymbol{X}_{i j t} \Delta+\vartheta_{t}+\psi_{i j}+\nu_{i j t}}
\end{gathered}
$$

Equation (1) is the first stage of a two stage system and Equation (2) is the second stage. The indices $i$ and $j$ denote individual countries, $i j$ denotes a given pair of countries, and $t$ denotes years. The sample is a panel of all countries that have reported bilateral trade data to the IMF between 1960 and 1990, six years before and seven years after the "golden era of containerization."

The dependent variable of ultimate interest, [MIDs] in Equation (2), is a count of all militarized dispute onsets within dyad $i j$ in year $t$. The endogenous variable of interest is [Trade]. This is the the total undirected volume of trade between the two countries in dyad $i j . \quad \boldsymbol{X}_{i j t}$ is a vector of time varying dyadic covariates. $\vartheta_{t}$ denotes year specific shocks. $\psi_{i j}$ denotes dyad fixed effects. [Both Containerized] $]_{i j t}$ is an indicator variable equal to one if both countries have a container port in year $t$ and zero otherwise. This construction is justified by the mutual nature of container technology and its rapid penetration into the transportation networks of participant 
countries. In practice, containerization is an absorbing state. [Both Containerized $]_{i j t}$ serves as the instrument. Once both countries have container ports, the cost of shipping goods between the pair is reduced which increases the total volume of trade. The coefficient of interest, $\beta$, is the estimated effect of an additional unit of trade on the incidence of conflict. A positive coefficient, $\beta>0$, indicates that, on average, an increase in trade increases the incidence of conflict in the dyad.

There are two main identifying assumptions. First, the instrument must exert a clear effect on the treatment. Figure 4.1 presents graphical evidence that containerization sharply increased trade. The figure plots the mean log of trade between dyads from 10 years prior to 10 years after containerization. While the overall slope is fairly constant throughout, a clear discontinuity occurs at the year of containerization. First stage results, presented in Figure 6.1, will confirm that containerization correlates strongly with increased trade. These results are also consistent with the analysis of Bernhofen et al., who report that containerization increased dyadic trade by about $17 \%$.

Second, the standard exclusion restriction must hold. In this case the restriction requires that the instrument, containerization, may only affect outcomes, MIDs, through the treatment, increased trade. An alternative formulation is that containerization cannot affect MIDs for dyads whose trading relationship is unaffected by containerization (the "never-takers" and "always-takers"). For example, containerization must not affect MIDs for dyads that would never trade more regardless of containerization status (the "never-takers"). This ensures that the two stage estimates reflect the average effect for observations that comply with the instrument, 


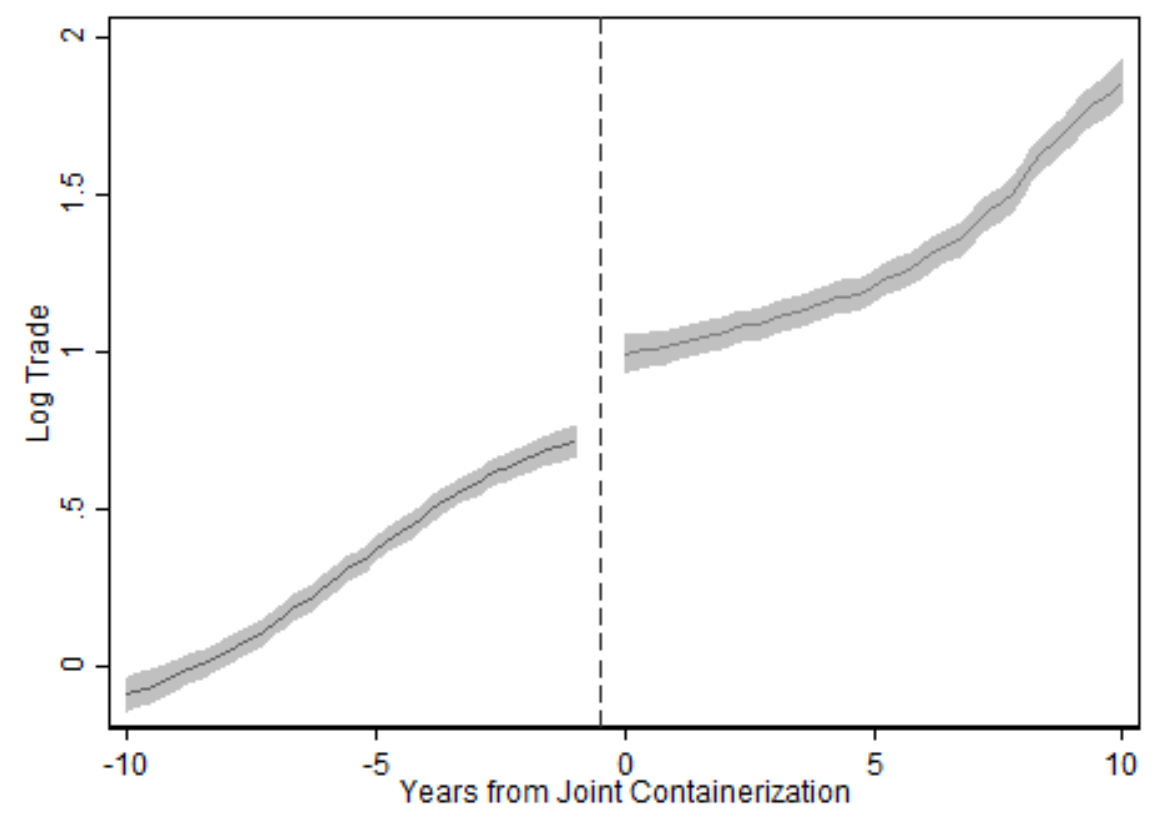

Figure 4.1: Average Bilateral Trade Before and After Containerization

the local average treatment effect. In this setting, compliers are dyads that trade more following containerization. In other words, the instrumental variable estimates are not driven by the effect of trade in dyads where containerization does not change the volume of bilateral trade.

The most serious concern is that containers might directly affect conflict occurrence. In point of fact, containers have been used to ship materiel. Furthermore, a container firm was notably contracted to ship goods to Vietnam for the US government starting in 1967 . These types of actions could conceivably cause conflict by lowering the actual dollar cost of fighting. Fortunately, this problem can be addressed with the data. Since container technology was adopted by different countries at different times, there are observations for which only one country is container- 
ized. This makes it possible to estimate the effects of just a single member of the dyad containerizing. If containerization affected conflict directly through this military channel, it should have some effect on conflict regardless of whether one or both constituents possess the technology. However, as Figures 6.1 and 6.2 in the results section show, the containerization of a single constituent impacts neither trade nor conflict. This alleviates concerns about a direct effect. Any direct mechanism that potentially violates the exclusion restriction must also account for the null effects of single containerization. Of course, containerization could also affect conflict by exerting an effect on an intervening variable. It is difficult, however, to think of any parameter, other than trade, that varies systematically along with containerization at the dyadic level. Based on these results, the most likely channel through which containerization affects conflict onset is through trade itself.

A separate but related concern is that containerization status was not randomly assigned to dyads as in a laboratory experiment. The timeline of containerization in Appendix B shows that the United States and European countries containerized first, followed by South American, Asian, and African nations (although not necessarily in that order). This is characteristic of the notorious difficulty in finding absolutely random variation in international relations panel data. For this reason, the analysis must assume that the assignment of containerization is ignorable after conditioning on covariates. IV estimation still provides consistent estimates when the exclusion restriction is weakened to hold conditionally (Angrist, 1998). Here the intent of including covariates is to obtain the solely technological portion of the shock, the effect of cost reduction, net of other time-varying effects that might correlate with 
containerization status. I implement this approach by including the literature's standard controls (Oneal and Russett, 1999; Barbieri, 2002; Gartzke, 2007), which will be discussed in Section 5. Note that the full set of controls is included in both equations. The only instrument in this setup is containerization. This avoids the critique of prior results being highly dependent on the particular parameters excluded. For example, Hegre, Oneal and Russett easily reversed the results of Keshk, Pollins and Reuveny by simply adding distance to the conflict equation.

Conditioning on covariates is of course a second-best strategy. Ignorability is not guaranteed to hold, since containerization may have depended on unobserved information. However, the sharp jump in trade depicted in Figure 4.1 indicates that containerization did have some exogenous, technological effect on trade. The time series in Figure 4.2 is similarly constructed but plots the average number of MID onsets per on the y-axis. Once again, there is a discontinuity at the year of containerization. For the instrument to be invalid some omitted information that varies at the dyadic level must cause these discontinuities.

Lastly, this study faces the usual trade-off involved in the choice of covariates (Rosenbaum, 2002; Kern and Hainmueller, 2009). While including more covariates maximizes the credibility of the ignorability assumption, including variables that are themselves affected by containerization can introduce post-treatment bias. On one end of the spectrum geographic continuity, physical distance, and common language are obviously causally prior to containerization. These are accounted for by the fixed effects. In the middle, containerization could affect polity scores, population, and colonization status via an indirect economic channel. At the other end containeriza- 


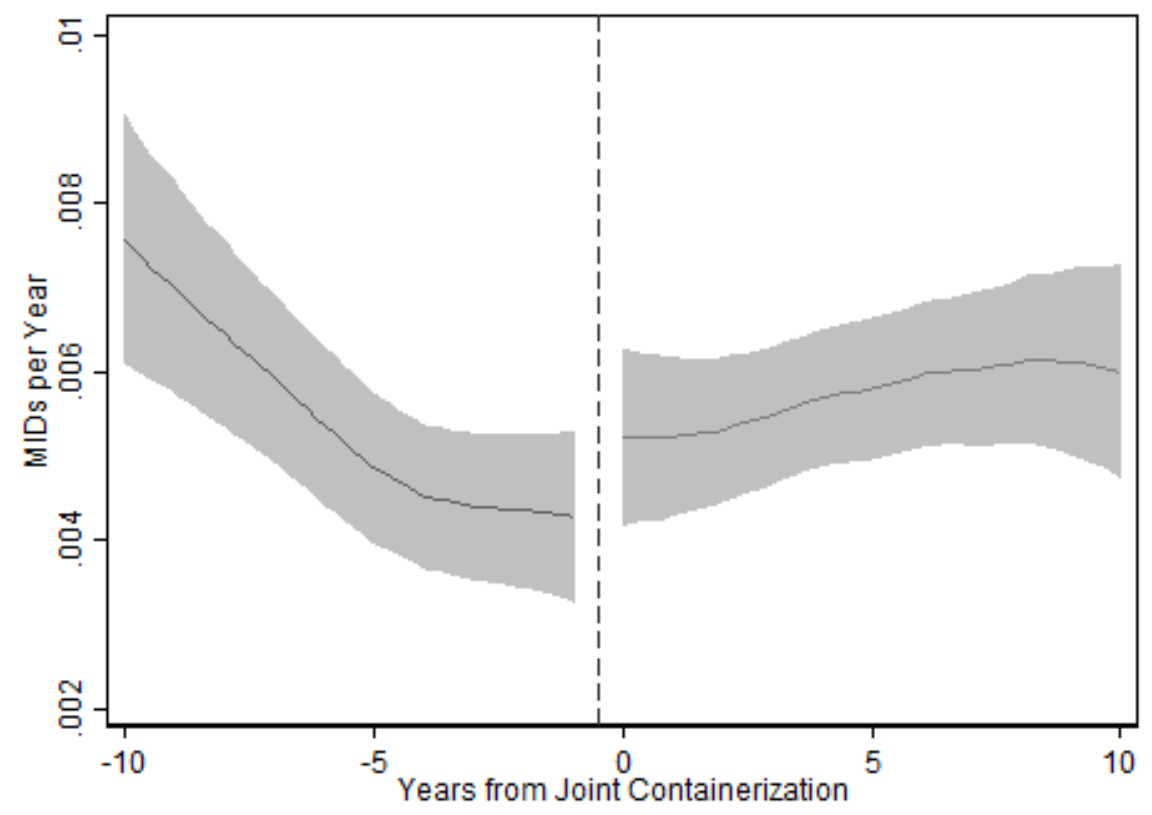

Figure 4.2: Average Onsets Per Year Before and After Containerization

tion is relatively more likely to influence GDP, CINC scores, and trade agreements. At the same time, these covariates help maximize the credibility of the ignorability assumption. Therefore, the results section presents three different specifications: a fixed effects model with only the containerization dummies; a fixed effects model including only the time-varying controls that are most likely pre-treatment; and finally a fixed effects model with the full set of time-varying covariates. All three sets of results are very similar, although the full model yields more precise estimates. It is worth noting that the full model does potentially recover the direct effect of containerization, its purely technological aspect, even in the presence of post-treatment effects. If the included covariates adequately proxy for trading potential, then the direct effect is estimated (Gelman and Hill, 2006). 
Aside from identification, estimating the system necessitates a number of practical choices. To start, Equation (1) takes the form of a gravity model. Gravity models predict trade volumes as a function of the size of trading partner's economies and bilateral resistance terms, such as distance or common language, which hinder or facilitate exchange (Tinbergen, 1962). Gravity specifications are commonly used to estimate the effect of a particular resistance term, in this case container technology, on trade. Traditionally, gravity equations are estimated via least squares by first taking the logarithm of the continuous terms on the right (e.g. GDP ${ }_{i}$ ) and left hand (e.g. Trade ${ }_{i j}$ ) sides of the equation. This has the obvious disadvantage that the log of zero is undefined. This necessitates dropping observations with zero trade from the sample, which may entail selection bias. An alternative approach, popular in applied microeconomic research, is to apply the inverse hyperbolic sine (IHS) transformation instead of logging. This transformation linearizes the equation in a fashion similar to logging but is also defined for zero.

To facilitate comparison with the existing simultaneous equations literature, the main text reports first and second stage results estimated via two stage least squares (2SLS) using the customary log transformation. Appendix D provides 2SLS estimates obtained after first transforming trade with the IHS function. With the IHS transformation, reduced-form and second stage results match those in the text. In the first stage, joint containerization still boosts trade by a large amount. However, a single containerizer leads to a relatively small but statistically significant drop in trade. To improve the first stage fit, and since single containerization still has no reduced-form effect, single containerization and joint containerization are both used 
as instruments. Another possibility is that the second stage, Equation (2), may be nonlinear. To account for this, appendix D also presents estimates obtained from a model with a linear first stage and probit second stage. These results concur with those presented in the main text.

\section{Data}

The data essential to this analysis are measurements of trade, conflict, and containerization. The unit of observation is the dyad-year throughout. The main models use the Correlates of War (CoW) bilateral trade data set (Barbieri, Keshk and Pollins, 2010) and the CoW dyadic Military Interstate Dispute (MID) data set (Maoz et al., 2018). Using these sources simplifies comparison with previous studies. In practice, almost all CoW trade observations after WWII are drawn from the International Monetary Fund's direction of trade statistics. These data are commonly used in both political science and economics. In very limited circumstances they are supplemented by archival research. For each dyad-year, I use the average of all reported import and export export flows. For example if the United States reported imports from and exports to Canada in 1962, but that year Canada only reported imports from the United States then trade is the sum of the three reports divided by three. This follows common practice (Rose, 2004). The dyadic Militarized Interstate Dispute data set is the standard measure of conflict in the literature (Keshk, Pollins and Reuveny, 2004; Gartzke, 2007; Oneal and Russett, 1999). It is an annual list of deliberate, overt, government-sanctioned, and government-directed threats, displays, 
or uses of force between pairs of countries. A variety of simple dyadic conflict measures are derived from this list: the number of MID onsets per year, the number of extant (new plus ongoing) MIDs per year, and a binary indicator for the presence or absence of any MIDs in a given year. These are, once again, standard quantities of interest.

Containerization data is taken from Bernhofen, El-Sahli and Kneller (2016). The authors define a country as containerized after its first recorded use of containers at either seaports or inland rail terminals. This encompasses land-locked countries like Austria and Switzerland that containerized via rail connection to the container seaports of Rotterdam and Hamburg. Back issues of the shipping industry periodical Containerization International contain announcements of all new container facility openings, which Bernhofen et al. used to compile a list of which countries containerized in which year.

These primary data are supplemented with a battery of controls which are standard in either the trade and conflict or macroeconomic trade literature: alliances, military capabilities, democracy, population, GDP, trade agreements, common language, and common colonizer. I use data from CoW affiliated sources for alliances (Gibler, 2009), shared IGO memberships (Pevehouse, Nordstrom and Warnke, 2004), military capabilities (Singer, Bremer and Stuckey, 1972), and common colonizer (Stinnett and Gochman, 2002). Measures of joint democracy are derived from Polity IV (Marshall, Gurr and Jaggers, 2016). Population and GDP data are from the Penn World Tables (Feenstra, Inklaar and Timmer, 2015). Shared membership in currency unions, the WTO, regional trade agreements, and various PTAs, as well 
as common language, are from the Dyadic Gravity data set (Gurevich and Herman, 2018).

\section{Empirical Results}

This section presents a series of results demonstrating that positive trade shocks increase the incidence of international conflict. The first set of results show an increase in trade following joint containerization, meaning that the instrument is strong. The next set indicate that joint containerization is also associated with more international conflict, evidence of the reduced form relationship. Note especially that single containerization status, when one trading partner has container technology and the other does not, is uncorrelated with both trade and conflict. This is empirical evidence in favor of the exclusion restriction. Finally, the IV estimates establish that trade, at least trade resulting from containerization, increases conflict incidence. The main paper presents regression results graphically, but tables are available in Appendix C. ${ }^{4}$ This section concludes with an array of robustness checks. The results presented in the main paper are from a logged first stage and a linear second stage specification. Since these are the most common functional forms in the literature, this facilitates interpretation and comparison. Appendix D contains results from two additional specifications: a first stage IHS transformation and a linear second stage, ${ }^{5}$ and a first stage log transformation and a second stage probit. ${ }^{6}$ The interpretation of the results is the same in all cases.

\footnotetext{
${ }^{4}$ See Table 11.1.

${ }^{5}$ See Table 12.1 .

${ }^{6}$ See Table 12.2 .
} 
The point estimates and $95 \%$ confidence intervals from three specifications of Equation (1), the first stage, presented in Figure 6.1 give an initial sense of the container revolution's effect on dyadic trade. The full specification, drawn with a solid orange line, includes all covariates discussed in Section 5. The pre-treatment only specification, drawn with a dotted blue line, contains only the covariates least likely to introduce post-treatment bias. The last model, represented by a dashed magenta line, includes only containerization status and fixed effects. There are 121,367 observations across 30 years and 6,931 dyads. All models include fixed effects, and all standard errors are clustered by dyad. The two most important estimates, Both containerized and Single containerizer, are at the top. The coefficients on Both containerized range from .17 in the full specification to .24 in the causally prior specification, and are all significant at well below the .01\% level. The effect of joint containerization is sizable. In the full specification, containerization brings an $18.5 \%$ increase in dyadic trade volumes. This is roughly in line with the $17 \%$ effect reported by Bernhofen et al. F-statistics for containerization, ranging from 19.389 in the full model to 29.738 in the pre-treatment specification, surpass the customary heuristic of 10 for IV estimation. In sum, joint containerization is a strong instrument, meaning that it has a clear and demonstrable impact on trade. 


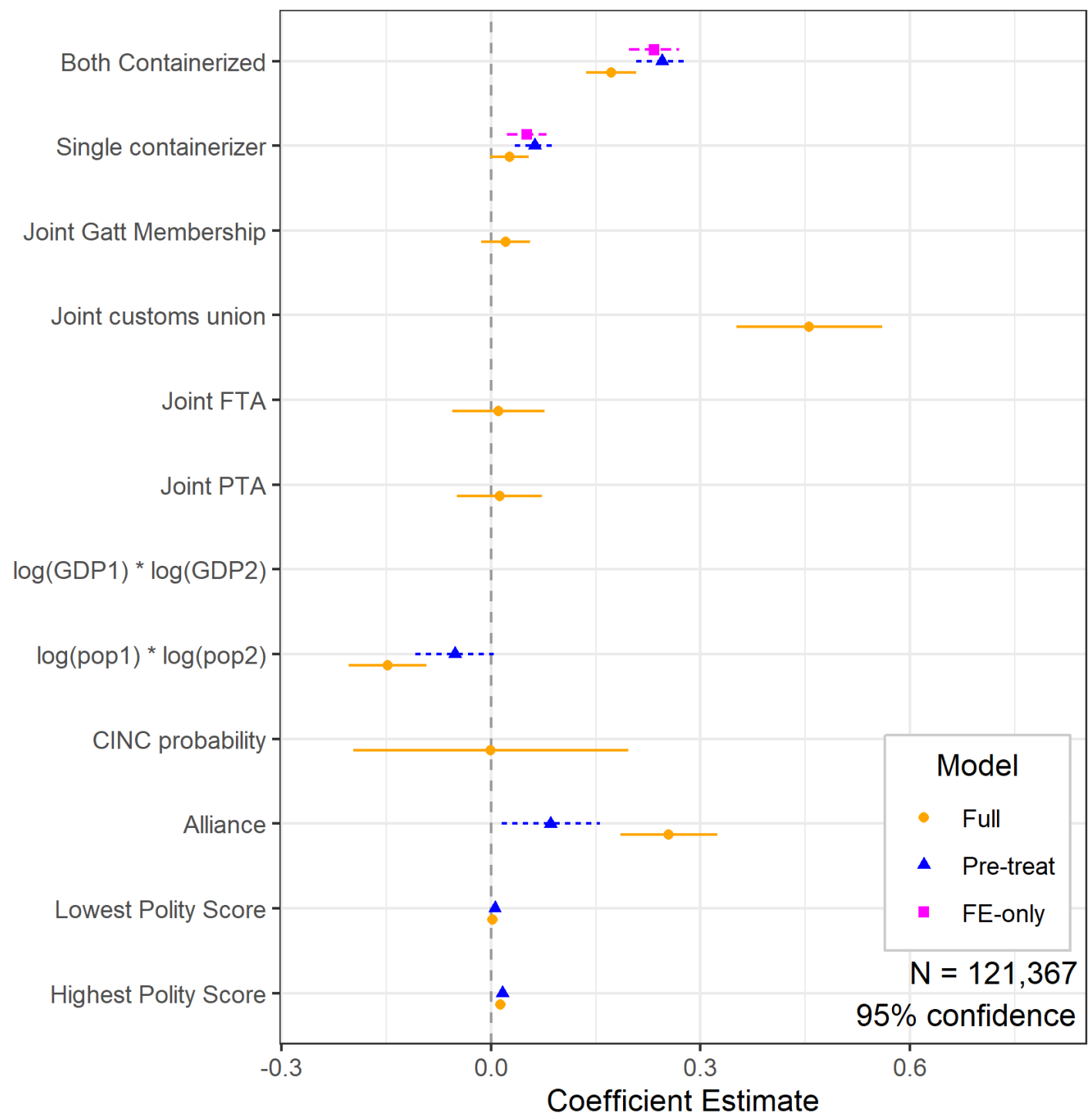

Figure 6.1: First Stage

Single containerization has a much smaller influence, both in terms of coefficients and $p$-values. In the pre-treatment model, its coefficient estimate is .063 and the associated $p$-value is .021. However, in the full specification the coefficient falls 
to .026 and the $p$-value inflates to .326 . Ultimately, having a single containerized constituent increases trade somewhere between $0 \%$ and $6 \%$ and a null effect is quite likely. This supports the identifying assumption that joint containerization boosts trade while single containerization does not.

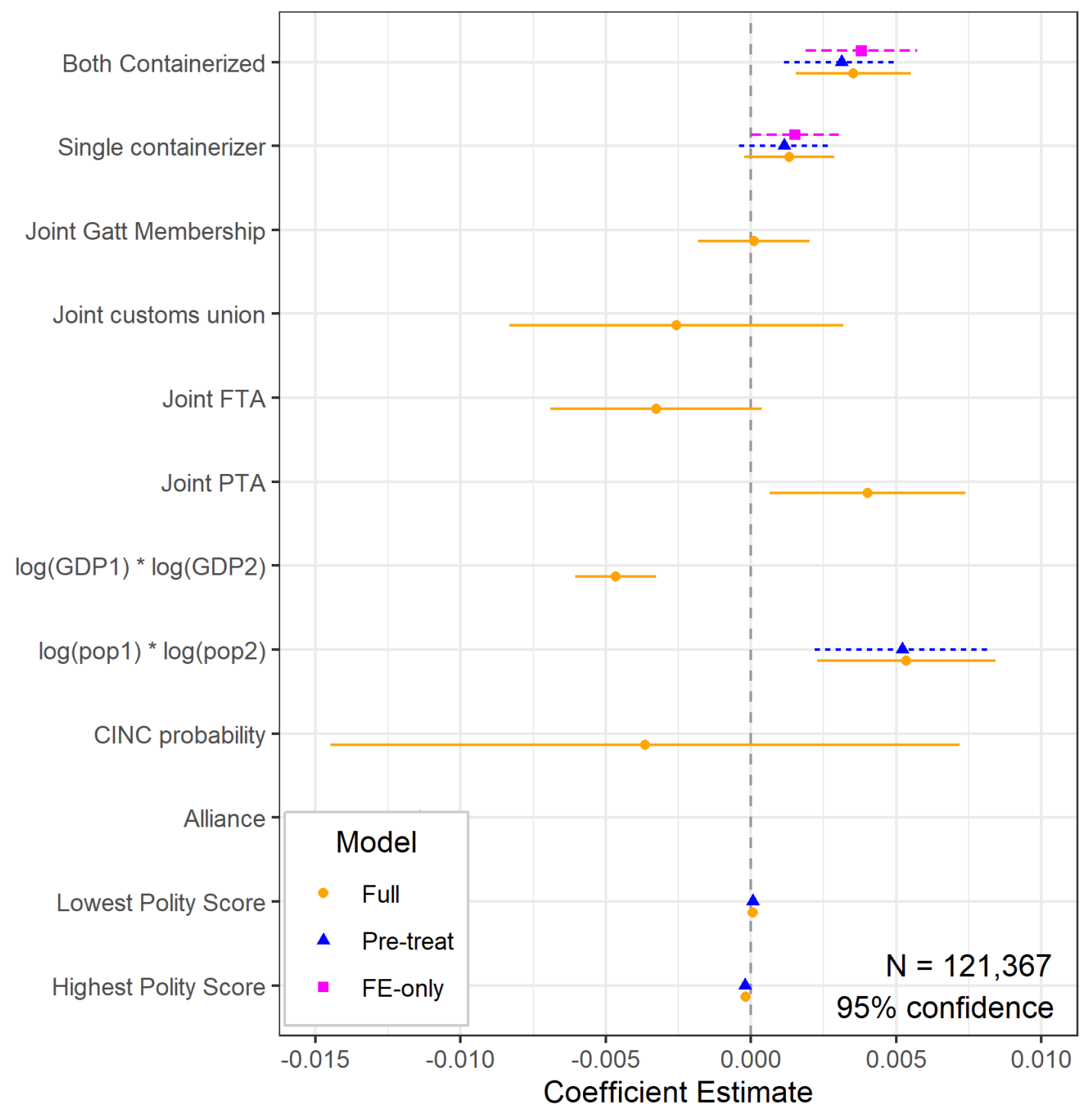

Figure 6.2: Reduced Form 
Figure 6.2 shows the reduced form estimates. Here the regressand is MID onsets and the regressors of interest are once again joint and single containerization. In all models, the coefficient on joint containerization is about .003. The baseline rate of conflict is .0035 per dyad-year, so this reduced form effect is substantial. All estimates are significant at below the $1 \%$ level. On the other hand, the effect of a single containerizer on MID incidence is never greater than .0015, and zero is well within the $95 \%$ confidence interval for all estimates. These reduced form results evidence two important relationships. First, joint containerization causes more conflict. Second, single constituent containerization does not. 


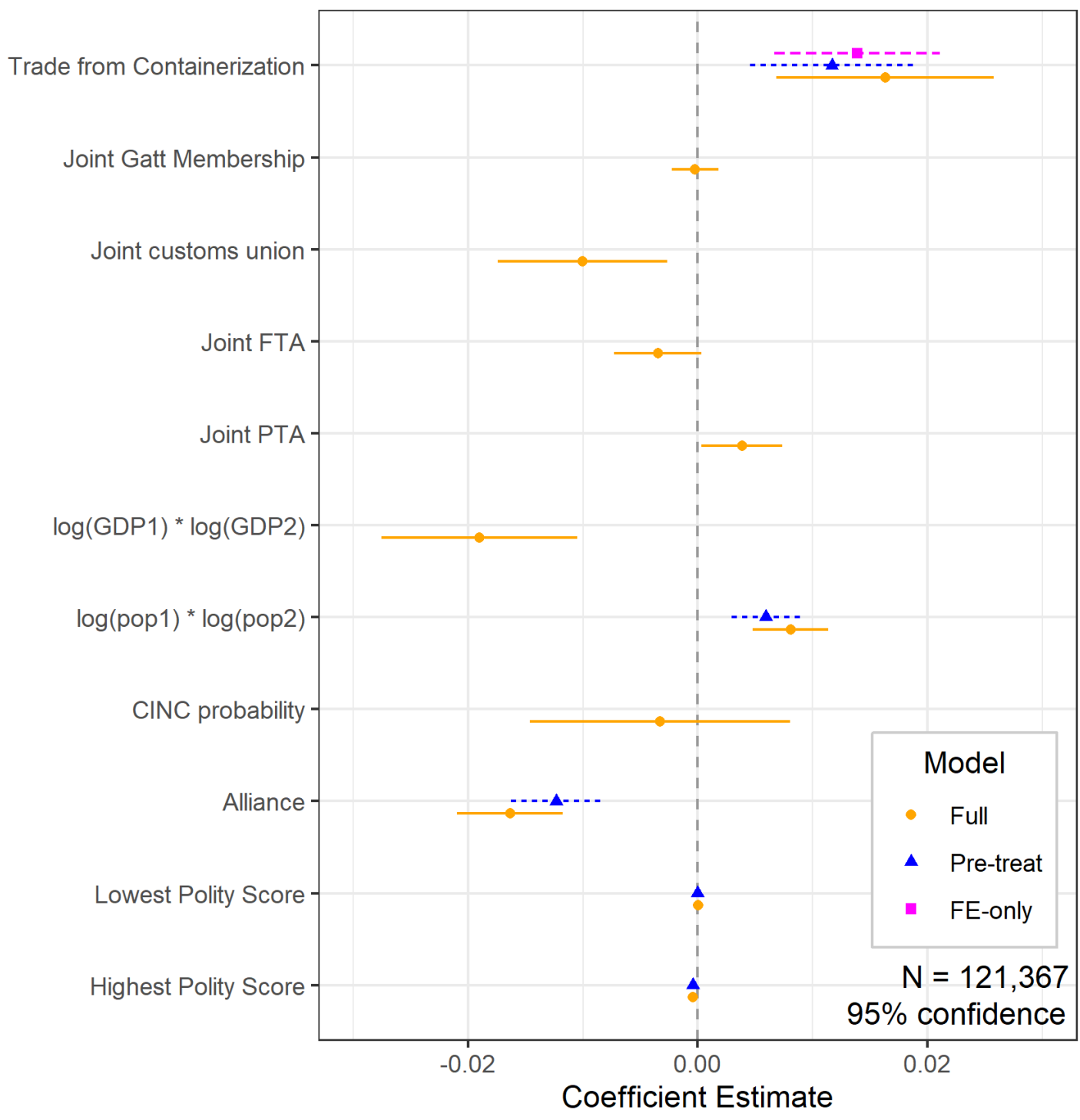

Figure 6.3: Second Stage

Lastly, Figure 6.3 depicts the IV estimates. Here, the coefficient of interest is the predicted change in conflict incidence caused by containerized trade. Estimates for this coefficient are at the top. The largest, .016, occurs in the full specification. 
The smallest, .012, occurs in the specification with only pre-treatmet variables. This indicates that a $15 \%$ trade shock, $15 \%$ being roughly the effect of containerization, results in between .0018 and .0024 more conflicts per dyad-year. The baseline conflict incidence rate is .0035 , so this increase is substantial. Once again, $p$-values for all estimates are below .01. This is one of the paper's two main results.

As discussed in Section 4, these results hold across a number of different functional forms and data transformation functions which are presented in appendix D. Aside from that, one might worry that outliers are driving the results. However, the results are robust to iteratively dropping G-8 members from the sample. In addition, temporal sample robustness checks show that the results do not hinge on a potentially arbitrary time period. Rerunning the analyses from 1955 to 1995, and from 1965 to 1985 , has no meaningful effect on the results.

Lastly, as with all previous studies of trade and conflict this paper has to contend with missing data. The two most important variables lacking complete coverage are GDP and trade itself. As of yet, there is still no panacea for missing data. I follow established practice by reporting results from extant data in the main text (Keshk, Reuveny and Pollins, 2010). In appendix D, I also report results from log-linear and IHS-linear specifications run on Gleditsch's (2002) global dataset of imputed trade, GDP, and population. ${ }^{7}$ Containerized trade increases conflict in both, however it is conventionally significant in neither (the respective $p$-values are .1167 and .21). Since Gleditsch's baseline data did not include containerization status, which in hindsight has a stark effect on trade, I also run both specifications on a smaller data set

\footnotetext{
${ }^{7}$ See Table 12.3 .
} 
comprised of only actually observed trade data and Gleditch's imputed populations and GDPs. ${ }^{8}$ This results in improved $p$-values (.0579 and .0755, respectively). To conclude, containerized trade increases conflict by a substantial magnitude in all models, but $p$-values are sometimes large with imputed data.

\section{Modelling Technological Shocks}

What explains these results? Technological shocks like containerization increase the total amount of value at stake. However, there is no reason to expect that the exact amount each party gains from the technology will be common knowledge. I show that when a standard opportunity cost model is extended to include uncertainty about each side's benefits from trade, the incidence of conflict can increase. This happens when one side suspects the other's gains may greatly outpace their own. This section begins by describing the model and introducing the proposition. It then demonstrates the model's intuition. Lastly, it relates the model's parameters to containerization and the empirical analysis. The proof is reserved for Appendix A.

In the baseline model without trade, two sides bargain over a resource of size $W$. Country A makes a demand, $x \in[0, W]$, which country B can either accept or reject. Rejection leads to fighting which country A wins with probability $p_{A}$ and both sides pay a cost $c_{A}, c_{B}>0$. The winner receives $W$. A's probability of winning, $p_{A}$, is common knowledge, but there is uncertainty about each side's costs. Specifically, country A knows $c_{A}$ but not $c_{B}$. Country A's belief about $c_{B}$ is distributed uniformly from zero to one. Figure 7.1 depicts this baseline case.

\footnotetext{
${ }^{8}$ See Table 12.4 .
} 


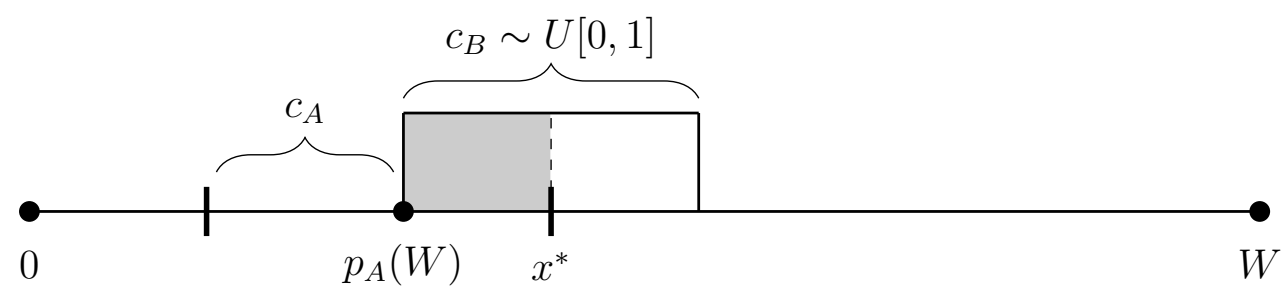

Figure 7.1: Baseline No Trade Game

A's belief about B's type is represented by the rectangle emanating from the point $p_{A}(W)$. A's goal is to choose a demand that maximizes their expected utility, factoring in both the probability that the demand is accepted or rejected and the consequences of rejection. A's demand is represented by $x^{*}$. The probability of rejection, which is increasing in $x^{*}$, is represented by the area of the grey shaded box. The more A demands, the greater the chances that B's costs are low enough that B would prefer fighting to acceptance. ${ }^{9}$ The consequences of rejection, A's expected conflict payoff, are represented by the leftmost tick mark at $p_{A}(W)-c_{A}$. So A's expected utility is equal to $\operatorname{Pr}\left[x^{*}<p_{A}(W)+c_{B}\right]\left(x^{*}\right)+\operatorname{Pr}\left[x^{*}>p_{A}(W)+c_{B}\right]\left(p_{A}(W)-c_{A}\right)$. In this baseline no trade game, A's equilibrium demand is $p_{A}(W)+\frac{1-c_{A}}{2}$, and it is rejected with a probability equal to $\frac{1-c_{A}}{2}$. Since A becomes more averse to a breakdown as its costs rise, these expressions are decreasing in $c_{A}$. That is, increasing $c_{A}$ incentivizes A to make lower demands which are rejected less frequently. To make this a bit more concrete, suppose that $c_{A}=\frac{8}{10}$. In this case, A's expected utility is $p_{A}(W)+\frac{1}{5}$ and bargaining breaks down in $10 \%$ of instances.

\footnotetext{
${ }^{9}$ For example, all types of B accept the demand $x^{*}=p_{A}(W)$ and all types reject the demand $x^{*}=p_{A}(W)+1$.
} 


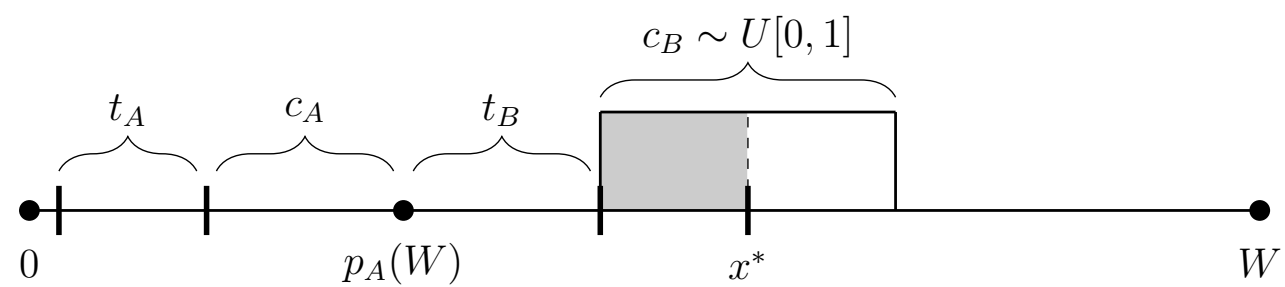

Figure 7.2: Common Knowledge Trade Benefits

Polachek and Xiang (2010) imbue each side with a positive trade benefit, $t_{A}, t_{B}>$ 0, that is common knowledge. This setup is illustrated in Figure 7.2. When trade benefits are perfectly known, increasing them unambiguously lowers the breakdown rate for two reasons. First, introducing $t_{B}$ creates a common knowledge bargaining range and, as usual, A monopolizes this entire surplus. Since $t_{B}$ is common knowledge, country A can simply add $t_{B}$ to any demand from the baseline model without affecting the likelihood that it is rejected. ${ }^{10} \mathrm{~A}$ does not want to jeopardize this surplus, which encourages A to make offers which are rejected less often than in the baseline case. Second, rejection now leads to the loss of $c_{A}$ and $t_{A}$ as opposed to only $c_{A}$ in the baseline game. This further incentivizes country A to moderate its demand. In this case, the breakdown rate is $\frac{1-\left(c_{A}+t_{A}+t_{B}\right)}{2}$ which is always lower than $\frac{1-c_{A}}{2}$.

This is not the case if there is asymmetric information about the benefits of trade. Specifically, suppose that country A knows $t_{A}$ but not $t_{B} \cdot{ }^{11}$ Instead, country A's belief about $t_{B}$ is distributed uniformly from zero to $Z$ with $Z>0$. A large $Z$ indicates that $\mathrm{A}$ believes trade is potentially very beneficial to $\mathrm{B}$, and a small

\footnotetext{
${ }^{10}$ For example, all types of B now accept the demand $x^{*}=p_{A}(W)+t_{B}$.

${ }^{11}$ Just as country A knows $c_{A}$ but not $c_{B}$.
} 
$Z$ indicates B's trade benefits will be meager at best. Aside from the fact that trade benefits are no longer common knowledge, all of the model's other parameters remain the same. To simplify the exposition, I also add the requirement that $W>$ $p_{A}(W)+1+Z$. This rules out cases where costs are extremely high, and or trade is enormously beneficial relative to the resource being contested. In these cases, A could simply demand all of $W$ while running virtually no risk of fighting. Under these conditions, the following proposition holds: 
Proposition 1. In the unique equilibrium of the extension of Polacheck Xiang (2010) described above, bargaining breaks down at a higher rate than in the no trade game under the following conditions:

$$
\begin{aligned}
& \frac{2}{3}\left(1-\left(c_{A}+t_{A}\right)\right) \leq Z<\frac{3}{2}+c_{A}+t_{A} \text { and } Z>-\frac{4\left(c_{A}{ }^{3}+2 c_{A} t_{A}-c_{A}{ }^{2}+c_{A} t_{A}{ }^{2}-2 c_{A} t_{A}-t_{A}{ }^{2}\right)}{\left(3 c_{A}-1\right)^{2}} \\
& \text { or } \\
& Z>\frac{3}{2}+c_{A}+t_{A} \text { and } Z>\frac{2\left(c_{A}+t_{A}\right)+1}{2 c_{A}}
\end{aligned}
$$

The proof is presented in Appendix A. This proposition means that regardless of the magnitude of A's trade benefits, there is always a $Z$, a maximum potential benefit for $\mathrm{B}$, that results in a greater rate of conflict relative to the no trade case. Figure 7.3 communicates the underlying intuition.

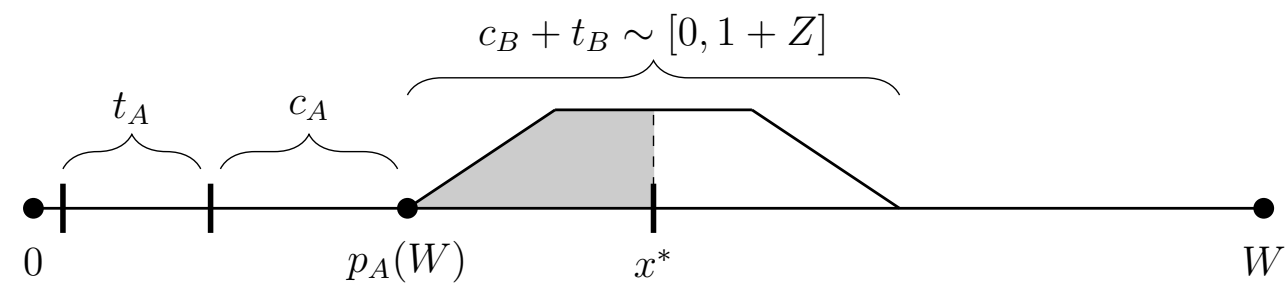

Figure 7.3: Asymmetric Information Trade Game

There are two key differences compared to the baseline game in Figure 7.1. Most noticeably, the shape of the distribution of A's beliefs about B's costs has changed. This is because the sum of two uniform distributions is their convolution, and their convolution is a trapezoid with a base length equal to the sum of their intervals. 
Intuitively, this is because it is relatively unlikely that both $c_{B}$ and $t_{B}$ are simultaneously low or simultaneously high. Since it is now more likely that A is facing a higher cost type, and higher cost types accept higher demands, A is incentivized to make a larger demand. The second difference is that the consequences of rejection, the conflict payoff, have worsened. Since trade is cut off during fighting, A now obtains $p_{A}(W)-c_{A}-t_{A}$ in the event that bargaining fails. This change incentivizes $\mathrm{A}$ to make a lower demand that is less likely to be rejected. Recall that $t_{B}$ is distributed uniformly from zero to $Z$. The proposition implies that for any $p_{A}(W), c_{A}$, and $t_{A}$ there is a $Z$ for which bargaining breaks down at a higher rate than in the no trade game. This is because the incentive to make more aggressive demands dominates the incentive to moderate as $Z$, A's belief about B's trade benefit, grows large relative to $c_{A}$ and $t_{A}$. For instance, if $c_{A}=\frac{8}{10}$, as in the no trade example, $t_{A}=\frac{2}{10}$, and $Z=\frac{6}{10}$ then A's equilibrium offer lies in the rising portion of the trapezoid. ${ }^{12}$ In that case, A's demand is equal to $p_{A}(W)+\frac{1}{3}\left(\sqrt{\left(c_{A}+t_{A}\right)^{2}+6 Z}-\left(c_{A}+t_{A}\right)\right)$. In this numerical example A's demand increases to $p_{A}(W)+.382$ and A's expected utility increases to $p_{A}(W)+.256$. The rejection rate, which is the percentage of the trapezoid's area between its origin at $p_{A}(W)$ and $p_{A}(W)+.382$, is about $12 \%$. This breakdown rate is about 2 percentage points higher compared to the no-trade example, even though A's fighting cost is unchanged and A strictly benefits from trade.

This model appropriately describes the advent of containerization if focusing the inquiry on uncertainty regarding benefits is justified. Containerization rapidly disrupts supply chains, upends the established commercial ecosystem, and creates

\footnotetext{
${ }^{12}$ See appendix A for details.
} 
new winners and losers. In this way, containerization's economic impact creates distinct domestic benefits that differ by country. Therefore, its benefits cannot be measured by simple summing raw trade tonnage or dollar volumes. Rather, these benefits are ultimately the result of complex social and political interactions and are difficult for opponents to know with certainty. By emphasizing that different countries might internalize the benefits of trade in different ways, this conception echoes key critiques of the liberal peace (Gelpi and Grieco, 2003; McDonald, 2004).

While the model gives analytical precedence to trade uncertainty, it is robust to containerization exerting commonly known affects on its other parameters. First, the results are unaffected if containerization directly affects the expected outcome of fighting. Since the breakdown rate is completely independent of $p_{A}$, it is also independent of any effect that containerization might have on the balance of power between both countries - so long as this effect is common knowledge. The model is also robust to containerization directly affecting $c_{A}$. The most likely avenue for this would be for containerization to reduce A's dollar cost of conflict. This lowers A's breakdown penalty, which pushes up A's demand and the breakdown rate. This characteristic of $c_{A}$ is both a strength and a weakness. On the one hand, it reinforces the notion that containers increase conflict. On the other, it mirrors the empirical model's exclusion restriction. To ensure that containers increase conflict by affecting trade uncertainty, and not via the cost-reduction channel, potential trade gains should supersede cost savings.

This game parallels the instrumental variables framework in two important ways. In the empirical model, identification rests on two key constructs: containerization's 
potential direct effect on conflict, and containerization's effect on conflict through trade. Ideally, the direct effect is null. In the theoretical model, direct effects are represented by the terms $c_{A}$ and $p_{A}$. From the results of the empirical model, it is clear that one constituent containerizing does not affect trade or conflict. Because trade is unaffected, single containerization status remains analogous to the baseline model. In the baseline model, changing $c_{A}$ or introducing uncertainty on $p_{A}$ changes the breakdown rate. Empirically, no change is observed. This lends credence to the assumption that container technology has a negligible affect on $c_{A}$ and does not introduce much uncertainty about $p_{A}$.

The second key construct is the effect containerization exerts on conflict through trade. This effect is related to the theoretical model's $t_{A}$ and $Z$ parameters. The empirical results show that joint containerization increases both trade and conflict. Since single containerization did not affect $c_{A}$ and $p_{A}$, it is also unlikely that joint containerization would have an affect through those terms. On the other hand, joint containerization results in a distinct trade increase. If the benefits of this increase are common knowledge, it is impossible for them to increase the conflict rate. This leaves $Z$, A's beliefs about $t_{B}$, as the most likely channel through which containerization increases conflict. Assessed holistically, the empirical and theoretical models form a consistent argument for this mechanism.

However, the empirical analysis is by no means a direct test of this theoretical argument. As a field, international relations is hampered by a lack of precise data on costs, benefits, and beliefs. Indeed, some of these important concepts may be unmeasureable. This paper cannot fully surmount this difficulty. For example, if $Z$ 
is systematically low relative to $c_{A}$ and $t_{A}$, then trade should result in less conflict on balance. Without accurate knowledge of $Z$, as well as the other cost and benefit parameters, it is not possible to directly test $Z$ as a causal mechanism. Rather, this paper argues that $Z$ is the most likely mechanism.

\section{Conclusion}

How does trade affect the likelihood of conflict? Despite extensive scholarship, there remains a lack of consensus. Inference has been handicapped by the reciprocal nature of trade and conflict. To address this difficulty, this paper studies the trade and conflict nexus within the context of the shipping container revolution. It offers two main contributions. First, it uses the exogenous technological shock of the shipping container revolution to identify the effect of trade on conflict. Perhaps surprisingly, trade gains induced by containerization substantially increase the incidence of conflict within country pairs. Second, it develops a new theoretical model to explain these

novel findings. Bargaining breakdowns are exacerbated when the exact benefits of trade are uncertain and one side suspects the other's gains are large relative to their own.

These empirical results shed new light on the observed relationship between trade and conflict. However, their broader implications are somewhat mixed. On the one hand, examining trade and conflict within the context of the intermodal revolution enables a strong research design and provides one set of cases that demonstrate the empirical relevance of trade on conflict. On the other hand, the current exercise of 
studying trade as the consequence of a technological shock limits the generalizability of the results. Although containerization is a historically interesting phenomenon, it is somewhat specific and extreme with regard to the size and speed of the trade boom it ushered in. For this reason, containerization necessitated a reanalysis of existing theories on interdependence and conflict. Overall, this article provides a roadmap for empirically assessing theories of trade and conflict, which should help inform future theory development and empirical tests.

The theoretical analysis also builds off considerable debate between the liberal and realist schools of international relations. Explaining how a trade shock increases conflict would be impossible without this existing work. However, classic treatments tend to be less clear about the specific mechanisms through which trade affects conflict. This is particularly true of the realist position, which holds that trade should have an inflammatory or at best null effect on conflict. The current contribution begins with the insights of existing work emphasizing important differences between domestic regime types. Chiefly, different countries will internalize the benefits of trade differently. Combining this condition with the fact that these differing benefits will be hard for opponents to know with certainty, especially during episodes of technological disruption, provides the springboard for understanding how increased trade increases conflict.

The advance of globalization did not end with containerization, nor did human innovation. New disruptive technologies, such as the internet, arrive frequently. Incidentally, these changes which enhance human productivity and cross-border collaboration may also destabilize the international system. The current research design 
may prove useful for studying the effects of these changes, contributing to a broader social science research agenda on innovation, interconnectedness, and security. 


\section{References}

Angrist, Joshua D. 1998. "Estimating the Labor Market Impact of Voluntary Military Service Using Social Security Data on Military Applicants." Econometrica $66(2): 249-288$.

URL: http://www.jstor.org/stable/2998558

Barbieri, Katherine. 1996. "Economic Interdependence: A Path to Peace or a Source of Interstate Conflict?" Journal of Peace Research 33(1):29-49.

Barbieri, Katherine. 2002. The Liberal Illusion: Does Trade Promote Peace? Ann Arbor: University of Michigan Press.

Barbieri, Katherine, Omar Keshk and Brian Pollins. 2010. "Correlates of War Project: International Trade Data, 1870-2006." ICPSR Data Holdings .

Benson, Brett V. and Emerson M.S. Niou. 2010. "Economic Interdependence and peace: A Game-Theoretic Analysis." Journal of East Asian Studies 7(1):35-59.

Benthem, Jeremyl. 1789. Principles of International Law.

Bernhofen, Daniel M., Zouheir El-Sahli and Richard Kneller. 2016. "Estimating the effects of the container revolution on world trade." Journal of International Economics 98:36-50.

Blainey, Geoffrey. 1988. Causes of War. New York: .

Copeland, Dale C. 1996. "Economic Interdependence and War: A Theory of Trade Expectations." International Security (4):5-41. 
Copeland, Dale C. 2015. Economic interdependence and war. Princeton University Press.

Crescenzi, Mark J.C. 2003. "Economic Exit, Interdependence, and Conflict." The Journal of Politics 65(3).

Doyle, Michael W. 1983. "Kant, Liberal Legacies, and Foreign Affairs." Philosophy Public Affairs 12(3):205-235.

URL: http://www.jstor.org/stable/2265298

Fearon, James D. 1995. "Rationalist Explanations for War." International Organization (49):379-414.

Feenstra, Robert C., Robert Inklaar and Marcel P. Timmer. 2015. "The Next Generation of the Penn World Table." American Economic Review 10(105):3150-82. An optional note.

Gartzke, Erik. 2007. "The Capitalist Peace." 51(1):166.

Gartzke, Erik and Jiakun Jack Zhang. 2015. "Trade and War." The Oxford Handbook of the Political Economy of International Trade.

Gartzke, Erik and Quan Li. 2003. "Measure for Measure: Concept Operationalization and the Trade Interdependence-Conflict Debate." Journal of Peace Research 40(5):553-571.

Gartzke, Erik, Quan Li and Charles Boehmer. 2001. "Investing in the Peace: Economic Interdependence and International Conflict." International Organization 55(2):391-438. 
Gelman, Andrew and Jennifer Hill. 2006. Data analysis using regression and multilevel/hierarchical models. Cambridge Univ. Press.

Gelpi, Christopher F. and Joseph M. Grieco. 2003. "Democracy, Interdependence, and the Sources of the Liberal Peace." Journal of Peace Research 45(1):17-36.

URL: https://doi.org/10.1177/0022343307084921

Gelpi, Christopher F. and Joseph M. Grieco. 2008. "Democracy, Interdependence, and the Sources of the Liberal Peace." Journal of Peace Research 45(1):17-36.

Gibler, Douglas M. 2009. "International military alliances, 1648-2008." CQ Press .

Goenner, Cullen F. 2011. "Simultaneity between Trade and Conflict Endogenous Instruments of Mass Destruction." 28(5):459.

Gowa, Joanne S. 1994. Allies, Adversaries, and International Trade. Princeton University Press Princeton, N.J.

URL: http://www.loc.gov/catdir/toc/prin031/93002178.html

Gowa, Joanne S. and Edward D. Mansfield. 1993. "Power Politics and International Trade." The American Political Science Review 87(2):408-420.

URL: http://www.jstor.org/stable/2939050

Grieco, Joseph M. 1988. "Anarchy and the Limits of Cooperation: A Realist Critique of the Newest Liberal Institutionalism." International Organization 42(3):485-507. URL: http://www.jstor.org/stable/2706r87

Grieco, Joseph, Robert Powell and Duncan Snidal. 1993. "The Relative-Gains Problem for International Cooperation." The American Political Science Review 
87(3):727-743.

URL: http://www.jstor.org/stable/2938747

Gurevich, Tamara and Peter Herman. 2018. "The Dynamic Gravity Dataset: Technical Documentation.".

Hegre, Havard, John R. Oneal and Bruce Russett. 2010. "Trade does promote peace: New simultaneous estimates of the reciprocal effects of trade and conflict." Journal of Peace Research 66(4):1155-1179.

Kant, Immanuel. 1795. Perpetual Peace. Broadview Press.

Kern, Holger and Jens Hainmueller. 2009. Political Analysis .

Keshk, Omar M.G., Brian M. Pollins and Rafael Reuveny. 2004. "Trade Still Follows the Flag: The Primacy of Politics in a Simultaneous Model of Interdependence and Armed Conflict." The Journal of Politics 66(4):763-774.

Keshk, Omar M.G., Rafael Reuveny and Brian M. Pollins. 2010. "Trade and Conflict: Proximity, Country Size, and Measures." Conflict Management and Peace Science $27(1): 3-27$.

URL: https://doi.org/10.1177/0265659009352137

Kim, Hyun Min and David L. Rousseau. 2005. "The Classical Liberals Were Half Right (or Half Wrong): New Tests of the 'Liberal Peace', 1960-88." Journal of Peace Research 42(5):523-543.

Kim, Soo Yeon. 1998. Ties that Bind: The Role of Trade in International Conflict Processes, 1950-1992 PhD thesis Yale University. 
Krugman, Paul. 2009. "Citigroup foundation special lecture, Festschrift paper in honor of Alan V. Deardorff.".

Levinson, Marc. 2006. The box: how the shipping container made the world smaller and the economy bigger. Princeton University.

Li, Quan and Rafael Reuveny. 2011. "Does Trade Prevent or Promote Interstate Conflict Initiation?" Journal of Peace Research 48(4):437-453.

Mansfield, Edward D. 1994. Power, Trade, and War. Princeton, NJ: Princeton University Press.

Maoz, Zeev, Paul L. Johnson, Jasper Kaplan, Fiona Ogunkoya and Aaron Shreve. 2018. "The Dyadic Militarized Interstate Disputes (MIDs) Dataset Version 3.0: Logic, Characteristics, and Comparisons to Alternative Datasets." Journal of Conflict Resolution p. 002200271878415.

Marshall, M., T. Gurr and K. Jaggers. 2016. POLITYTM IV PROJECT Political Regime Characteristics and Transitions, 1800-2015 Dataset Users' Manual. Technical report Centre for Systemic Peace. 1st ed.

Martin, Philippe, Thierry Mayer and Mathias Thoenig. 2008. "Make Trade not War?" The Review of Economic Studies. 75(3):865-900.

Mastanduno, Michael. 1991. "Do Relative Gains Matter? Americas Response to Japanese Industrial Policy." International Security 16(1):73.

McDonald, Patrick J. 2004. "Peace through Trade or Free Trade?" Journal of Conflict Resolution 48(4):547-572. 
Mesquita, Bruce Bueno De, Alastair Smith, Randolph M. Siverson and James D. Morrow. 2003. "The Logic of Political Survival.".

Morrow, James D. 1999. "How Could Trade Affect Conflict?" Journal of Peace Research 36(4):481-489.

URL: http://www.jstor.org/stable/425300

Oneal, John R., Frances H. Oneal, Zeev Maoz and Bruce Russett. 1996. "The Liberal Peace: Interdependence, Democracy, and International Conflict, 1950-85." Journal of Peace Research 33(1):11-28.

URL: http://www.jstor.org/stable/425131

Oneal, J.R. and Bruce Russett. 1999. "The Kantian Peace." World Politics (52):1-37.

Papayoanou, Paul A. 1996. "Interdependence, Institutions, and the Balance of Power: Britain, Germany, and World War I." International Security 20(4):42-76.

URL: http://www.jstor.org/stable/2539042

Pevehouse, Jon C., Timothy Nordstrom and Kevin Warnke. 2004. "The COW-2 International Organizations Dataset Version 2.0." Conflict Management and Peace Science (21):101-119. An optional note.

Polachek, Simon W. 1980. "Conflict and Trade." Journal of Conflict Resolution $(24): 55-78$.

Polachek, Solomon W. and Jun Xiang. 2010. "How Opportunity Costs Decrease the Probability of War in an Incomplete Information Game." International Organization 64(1):133-144. 
Pollins, Brian M. 1989. "Does Trade Still Follow the Flag?" American Political Science Review 83(2):465-480.

Rose, Andrew K. 2004. "Do We Really Know That the WTO Increases Trade?" The American Economic Review 94(1):98-114.

URL: http://www.jstor.org/stable/3592771

Rosenbaum, Paul R. 2002. Observational studies. Springer.

Singer, J. David, Stuart Bremer and John Stuckey. 1972. Capability Distribution, Uncertainty, and Major Power War, 1820-1965. Beverly Hills: Sage pp. 19-48. book is Peace, War, and Numbers.

Solingen, Etel. 2003. Internationalization, Coalitions, and Regional Conflict and Cooperation. University of Michigan Press pp. 60-86.

URL: http://www.jstor.org/stable/10.3998/mpub.11952.7

Spaniel, William and Iris Malone. 2019. "The Uncertainty Tradeoff: Re-Examining Opportunity Costs and War." International Studies Quarterly .

Stinnett, Douglas M., Jaroslav Tir Philip Schafer Paul F. Diehl and Charles Gochman. 2002. "The Correlates of War Project Direct Contiguity Data, Version 3." Conflict Management and Peace Science 19(2):58-66. An optional note.

Tinbergen, Jan. 1962. Shaping the world economy: suggestions for an International Economic Policy. Twentieth Century Fund. 
Ward, Michael D., Randolph M. Sieverson and Cao Xun. 2007. "Democracies, and Dependencies: A Reexamination of the Kantian Peace." American Journal of Political Science 51(3):583-601. 


\section{Appendix A: Proof of Proposition 1}

The proof of the proposition proceeds in three steps. The first step provides the equilibrium of the game with asymmetric trade information described in the main text. The second step demonstrates uniqueness. The final step shows which values for $Z$ yield a higher incidence of conflict than in Polacheck and Xiang's no trade game.

\section{Equilibrium}

Country B knows $c_{B}+t_{B}$ and we describe A's beliefs about $c_{B}+t_{B}$ with probability density $f\left(c_{B}+t_{B}\right)$ with full support on $[0,1+Z]$. Let $x$ represent A's demand. Country B will reject any $x>p_{A}(W)+c_{B}+t_{B}$ and accept any $x \leq p_{A}(W)+c_{B}+t_{B}$. Note that B will accept $x=p_{A}(W)$ for certain, so A will never offer $x<p_{A}(W)$. Hence, the crux of A's decision is how much to demand in addition to $p_{A}(W)$. Let $\Delta$ represent this additional amount, and define $U_{A}(\Delta)$ as A's additional utility from attaining $\Delta$ :

$$
U_{A}(\Delta)=\int_{0}^{\Delta}\left(-\left(c_{A}+t_{A}\right)\right) f\left(c_{B}+t_{B}\right) d\left(c_{B}+t b\right)+\int_{\Delta}^{(1+Z)}(\Delta) f\left(c_{B}+t_{B}\right) d\left(c_{B}+t_{B}\right)
$$

The first order condition is:

$$
\frac{\partial U_{A}}{\partial \Delta}=-\left(c_{A}+t_{A}\right) f(\Delta)+1-F(\Delta)-\Delta f(\Delta)
$$

Second order conditions will be explicitly verified in the subsequent analysis. Setting 
the first order condition equal to zero and rearranging terms yields the following equality:

EQ (1):

$$
\frac{1}{\Delta+\left(c_{A}+t_{A}\right)}=\frac{f(\Delta)}{1-F(\Delta)}
$$

The equilibrium demand, $x^{*}$, is the solution for $\Delta$ in EQ (1) plus $p_{A}(W)$. In the game with asymmetric trade information, $f$ is the convolution of two uniform distributions: $c_{B} \sim U[0,1]$ and $t_{B} \sim U[0, Z]$ with $Z>0$. Because of the characteristics of the uniform distribution, there are two distinct cases to consider: $Z \leq 1$ and $Z>1$. Since the pdf of the convolution of two uniform distributions is not smooth, each case will have five subcases.

Case I: $Z \leq 1$

In this case,

$$
f= \begin{cases}0 & \text { for } \Delta<0 \\ \frac{\Delta}{Z} & \text { for } 0 \leq \Delta<Z \\ 1 & \text { for } Z \leq \Delta<1 \\ \frac{-\Delta+(1+Z)}{Z} & \text { for } 1 \leq \Delta<1+Z \\ 0 & \text { for } \Delta \geq 1+z\end{cases}
$$

and, 


$$
F= \begin{cases}0 & \text { for } \Delta<0 \\ \frac{\Delta^{2}}{2 Z} & \text { for } 0 \leq \Delta<Z \\ \frac{2 \Delta-Z}{2} & \text { for } Z \leq \Delta<1 \\ \frac{-1+2 \Delta+2 Z \Delta-Z^{2}-\Delta^{2}}{2 Z} & \text { for } 1 \leq \Delta<1+Z \\ 1 & \text { for } \Delta \geq 1+z\end{cases}
$$

subcase I.i: $\Delta^{*}$ cannot be $<0$, which rules out subcase (I.i).

subcase I.ii: Suppose $0 \leq \Delta^{*}<Z$. Substituting $f=\frac{\Delta}{Z}$ and $F=\frac{\Delta^{2}}{2 Z}$ into EQ. (1) and solving for $\Delta$ gives $\Delta^{*}=\frac{1}{3}\left(\sqrt{\left(c_{A}+t_{A}\right)^{2}+6 z}-\left(c_{A}+t_{A}\right)\right)$. As long as $\frac{2}{3}\left(1-\left(c_{A}+t_{A}\right)\right)<Z<1$, then $\Delta^{*}=\frac{1}{3}\left(\sqrt{\left(c_{A}+t_{A}\right)^{2}+6 z}-\left(c_{A}+t_{A}\right)\right) \in[0, Z)$. The second order condition at this point is $\frac{-\left(c_{A}+t_{A}\right)-3 \Delta}{Z}$, which is negative.

subcase I.iii: Suppose $Z \leq \Delta^{*}<1$. Substituting $f=1$ and $F=\frac{2 \Delta-Z}{2}$ into EQ. (1) and solving for $\Delta$ gives $\Delta^{*}=\frac{2-2\left(c_{A}+t_{A}\right)+Z}{4}$. As long as $0<Z<\frac{2}{3}\left(1-\left(c_{A}+t_{A}\right)\right)$, then $\Delta^{*}=\frac{2-2\left(c_{A}+t_{A}\right)+Z}{4} \in[Z, 1)$. The second order condition at this point is -2 . subcase I.iv: Suppose $1 \leq \Delta^{*}<1+Z$. Substituting $f=\frac{-\Delta+(1+Z)}{Z}$ and $F=$ $\frac{-1+2 \Delta+2 Z-Z 2-\delta^{2}}{2 Z}$ into EQ. (1) and solving for $\Delta$ gives $\Delta^{*}=\frac{-2\left(c_{A}+t_{A}\right)+Z+1}{3}$. This offer is made when $Z>2+2\left(c_{A}+t_{A}\right)$. However, this is a contradiction since $2+2\left(c_{A}+t_{A}\right)>1$ and $Z<1$. This rules out subcase (I.iv).

subcase I.v: Suppose $\Delta^{*} \geq 1+Z$. Then $\frac{f(\Delta)}{1-F(\Delta)}$ is undefined. This rules out subcase (I.v).

Case II: $Z>1$ 
In this case,

$$
f= \begin{cases}0 & \text { for } \Delta<0 \\ \frac{\Delta}{Z} & \text { for } 0 \leq \Delta<1 \\ \frac{1}{Z} & \text { for } 1 \leq \Delta<Z \\ \frac{-\Delta+(1+Z)}{Z} & \text { for } Z \leq \Delta<1+Z \\ 0 & \text { for } \Delta \geq 1+Z\end{cases}
$$

and,

$$
F= \begin{cases}0 & \text { for } \Delta<0 \\ \frac{\Delta^{2}}{2 Z} & \text { for } 0 \leq \Delta<1 \\ \frac{2 \Delta-1}{2 Z} & \text { for } 1 \leq \Delta<Z \\ \frac{-1+2 \Delta+2 Z \Delta-Z^{2}-\Delta^{2}}{2 Z} & \text { for } 1 \leq \Delta<1+Z \\ 1 & \text { for } \Delta \geq 1+Z\end{cases}
$$

subcase II.i: $\Delta^{*}$ cannot be $<0$, which rules out subcase (II.i).

subcase II.ii: Suppose $0 \leq \Delta^{*}<1$. Substituting $f=\frac{\Delta}{Z}$ and $F=\frac{\Delta^{2}}{2 Z}$ into EQ. (1) and solving for $\Delta$ gives $\Delta^{*}=\frac{1}{3}\left(\sqrt{\left(c_{A}+t_{A}\right)^{2}+6 z}-\left(c_{A}+t_{A}\right)\right)$, which is the same as in (I.ii). As long as $1 \leq Z<\frac{3}{2}+\left(c_{A}+t_{A}\right)$, then $\Delta^{*}=\frac{1}{3}\left(\sqrt{\left(c_{A}+t_{A}\right)^{2}+6 z}-\right.$ $\left.\left(c_{A}+t_{A}\right)\right) \in[0,1)$. The second order condition at this point is $\frac{-\left(c_{A}+t_{A}\right)-3 \Delta}{Z}$, which is negative.

subcase II.iii: Suppose $1 \leq \Delta^{*}<Z$. Substituting $f=\frac{1}{Z}$ and $F=\frac{2 \Delta-1}{2 Z}$ into 
EQ. (1) and solving for $\Delta$ gives $\Delta^{*}=\frac{2 Z-2\left(c_{A}+t_{A}\right)+1}{4}$. As long as $Z>\frac{3}{2}+\left(c_{A}+t_{A}\right)$, then $\Delta^{*}=\frac{2 Z-2\left(c_{A}+t_{A}\right)+1}{4} \in[1, Z)$. The second order condition at this point is $\frac{-4}{2 Z}$, which is negative.

subcase II.iv: Suppose $1 \leq \Delta^{*}<1+Z$. Substituting $f=\frac{-\Delta+(1+Z)}{Z}$ and $F=\frac{-1+2 \Delta+2 Z-Z 2-\delta^{2}}{2 Z}$ into EQ. (1) and solving for $\Delta$ gives $\Delta^{*}=\frac{-2\left(c_{A}+t_{A}\right)+Z+1}{3}$, which is the same as in (II.iv). This offer is made when $Z<\frac{1-2\left(c_{A}+t_{A}\right)}{2}$. However, this is a contradiction since $\frac{1-2\left(c_{A}+t_{A}\right)}{2}<1$ and $Z>1$. This rules out subcase (II.iv).

subcase II.v: Suppose $\Delta^{*} \geq 1+Z$. Then $\frac{f(\Delta)}{1-F(\Delta)}$ is undefined. This rules out subcase (II.v).

Combining the solutions from all surviving subcases and adding $p_{A}(W)$ gives A's equilibrium demand, $x^{*}$ :

$x^{*}= \begin{cases}\mathrm{p}_{A}(W)+\frac{2-2\left(c_{A}+t_{A}\right)+Z}{4} & \text { for } 0 \leq Z<\frac{2}{3}\left(1-\left(c_{A}+t_{A}\right)\right) \\ \mathrm{p}_{A}(W)+\frac{1}{3}\left(\sqrt{\left(c_{A}+t_{A}\right)^{2}+6 z}-\left(c_{A}+t_{A}\right)\right) & \text { for } \frac{2}{3}\left(1-\left(c_{A}+t_{A}\right)\right) \leq Z<\frac{3}{2}+\left(c_{A}+t_{A}\right) \\ \mathrm{p}_{A}(W)+\frac{2 Z-2\left(c_{A}+t_{A}\right)+1}{4} & \text { for } Z \geq \frac{3}{2}+\left(c_{A}+t_{A}\right)\end{cases}$

Hence, the equilibrium solution is that A offers $x^{*}$ and B rejects if $x^{*}>p_{A}(W)+$ $c_{B}+t_{B}$ and accepts otherwise.

\section{Uniqueness}


The right hand side of EQ. (1), $\frac{f(\Delta)}{1-F(\Delta)}$, is the hazard rate. Since the left hand side of EQ (1) is strictly decreasing in $\Delta$, A sufficient condition for a unique equilibrium is that the hazard rate is strictly increasing in $\Delta$. This ensures that the curves described by the left hand side and right hand side expressions cross at most once. For subcases I.ii, I.iii, II.ii, and II.iii, it is easy to verify that the hazard rate's numerator, $f(\Delta)$, is weakly increasing in $\Delta$ and its denominator, $1-F(\Delta)$, is strictly decreasing in $\Delta$. For subcases I.iv and II.iv the hazard rate simplifies to $\frac{2}{1+Z-\Delta}$, which is strictly increasing in $\Delta$. Hence, the hazard rate is strictly increasing and the equilibrium described in part (1) is unique.

\section{Proof of Proposition 1}

In Polacheck \& Xiang's no-trade game, the bargaining failure rate is $\left(1-c_{A}\right) / 2$. In the game with asymmetric trade information, the bargaining failure rate is $F\left(\Delta^{*}\right)$. Hence bargaining breaks down at the following rates:

$$
F(\Delta *)= \begin{cases}\frac{2\left[\frac{2-2\left(c_{A}+t_{A}\right)+Z}{4}\right]-Z}{2} & \text { for } 0 \leq Z<\frac{2}{3}\left(1-\left(c_{A}+t_{A}\right)\right) \\ \frac{\left[\frac{1}{3}\left(\sqrt{\left(c_{A}+t_{A}\right)^{2}+6 z}-\left(c_{A}+t_{A}\right)\right)\right]^{2}}{2 Z} & \text { for } \frac{2}{3}\left(1-\left(c_{A}+t_{A}\right)\right) \leq Z<\frac{3}{2}+\left(c_{A}+t_{A}\right) \\ \frac{2\left[\frac{2 Z-2\left(c_{A}+t_{A}\right)+1}{4}\right]-1}{2 Z} & \text { for } Z \geq \frac{3}{2}+\left(c_{A}+t_{A}\right)\end{cases}
$$


When $0 \leq Z<\frac{2}{3}\left(1-\left(c_{A}+t_{A}\right)\right)$ :

$$
\frac{2\left[\frac{2-2\left(c_{A}+t_{A}\right)+Z}{4}\right]-Z}{2}>\frac{1-c_{A}}{2}
$$

is true when:

$$
\begin{gathered}
2\left[\frac{2-2\left(c_{A}+t_{A}\right)+Z}{4}\right]-Z>1-c_{A} \\
2-2\left(c_{A}+t_{A}\right)-Z>2-2 c_{A} \\
Z<-2 t_{A}
\end{gathered}
$$

Which is a contradiction, since $Z$ and $t_{A}$ are both positive. So the breakdown rate in the trade game never exceeds the breakdown rate in the no trade game when $0 \leq Z<\frac{2}{3}\left(1-\left(c_{A}+t_{A}\right)\right)$.

When $\frac{2}{3}\left(1-\left(c_{A}+t_{A}\right)\right) \leq Z<\frac{3}{2}+\left(c_{A}+t_{A}\right)$ :

$$
\frac{\left[\frac{1}{3}\left(\sqrt{\left(c_{A}+t_{A}\right)^{2}+6 z}-\left(c_{A}+t_{A}\right)\right)\right]^{2}}{2 Z}>\frac{1-c_{A}}{2}
$$

is true when: 


$$
\frac{1}{3}<c_{A}<1 ; t_{A}>-c_{A} ; \text { and } Z>-\frac{4\left(c_{A}^{3}+2 c_{A}^{2} t_{A}-c_{A}^{2}+c_{A} t_{A}^{2}-2 c_{A} t_{A}-t_{A}^{2}\right)}{\left(3 c_{A}-1\right)^{2}}
$$

Note that $t_{A}>-c_{A}$ is always true since both are positive.

When $Z \geq \frac{3}{2}+\left(c_{A}+t_{A}\right)$ :

$$
\frac{2\left[\frac{2 Z-2\left(c_{A}+t_{A}\right)+1}{4}\right]-1}{2 Z}>\frac{1-c_{A}}{2}
$$

is true when:

$$
\begin{gathered}
2\left[\frac{2 Z-2\left(c_{A}+t_{A}\right)+1}{4}\right]-1>Z\left(1-c_{A}\right) \\
\frac{2 Z-2\left(c_{A}+t_{A}\right)+1}{2}-1>Z\left(1-c_{A}\right) \\
\frac{2 Z-2\left(c_{A}+t_{A}\right)-1}{2}>Z\left(1-c_{A}\right) \\
2 Z-2\left(c_{A}+t_{A}\right)-1>2 Z-2 Z c_{A} \\
2 Z c_{A}>2\left(c_{A}+t_{A}\right)+1
\end{gathered}
$$




$$
Z>\frac{2\left(c_{A}+t_{A}\right)+1}{2 c_{A}}
$$

Note that in this case there is no restriction on $c_{A}$ or $t_{A}$, so there is always a $Z$ for which the breakdown rate in the asymmetric trade information game exceeds that of the no trade game.

This demonstrates the proposition.

\section{Appendix B: Containerization Timeline}

\begin{tabular}{|c|c|c|c|c|c|}
\hline 1966 & West Germany $(\mathbb{P})^{a}$ & Netherlands $(\mathbf{P})^{a}$ & $\operatorname{UK}(\mathrm{P})(\mathrm{R})^{2}$ & USA $(P)^{a}$ & India (R) \\
\hline \multirow[t]{3}{*}{1968} & Australia $(P)^{a}$ & Austria(R)a & Belgium $(\mathrm{P})^{a}$ & Canada $(\mathrm{P})^{a}$ & $\operatorname{Denmark}(\mathrm{P})^{\mathrm{a}}$ \\
\hline & East Germany(R) & France $(P)^{a}$ & Hungary(R) & Ireland $(\mathbf{R})^{2}$ & Italy $(\mathrm{P})^{\mathrm{a}}$ \\
\hline & Spain $(R)^{a}$ & Sweden $(R)^{a}$ & Switzerland $(\mathbf{R})^{a}$ & Taiwan(P) & \\
\hline 1969 & Finland $(P)^{a}$ & Yugoslavia(R) & Japan $(P)^{2}$ & Norway $(\mathbf{R})^{a}$ & Portugal $(P)^{2}$ \\
\hline 1970 & $\begin{array}{l}\text { Hong Kong }(\mathbf{P}) \\
\text { Singapore }(\mathbf{P})\end{array}$ & USSR(R) & Greece $(P)^{a}$ & Israel(P) & Romania(R) \\
\hline 1971 & Cote D'lvoire(P) & New Zealand $(\boldsymbol{P})^{2}$ & Philippines (P) & Poland (P) & Trinidad(P) \\
\hline 1972 & Bulgaria(R) & Czechoslowakia(R) & & & \\
\hline 1973 & Bahamas $(\mathrm{P})$ & Brazil(P) & Iceland $(\mathrm{P})^{a}$ & Jamaica(P) & Malaysia(P) \\
\hline 1974 & $\begin{array}{l}\text { Cameroon }(\mathrm{P}) \\
\text { South Africa }(\mathrm{P})\end{array}$ & Chile (P) & Colombia(R) & Nigeria $(P)$ & Panama(R) \\
\hline 1975 & $\begin{array}{l}\text { Barbados(P) } \\
\text { Thailand }(\mathrm{P})\end{array}$ & Honduras $(\mathrm{P})$ & Indonesia(P) & Korea Rep(P) & Peru(P) \\
\hline 1976 & $\begin{array}{l}\text { Argentina }(\mathrm{P}) \\
\text { Saudi Arabia(P) }\end{array}$ & $\begin{array}{l}\operatorname{Benin}(P) \\
\operatorname{UAE}(P)\end{array}$ & $\operatorname{Kenya}(\mathrm{P})$ & Mexico(P) & N. Caledonia(P) \\
\hline 1977 & $\begin{array}{l}\text { Bahrain(P) } \\
\text { Kuwait(P) }\end{array}$ & $\begin{array}{l}\text { Cyprus(P) } \\
\text { Lebanon(P) }\end{array}$ & $\begin{array}{l}\text { Ghana(P) } \\
\text { Morocco(P) }\end{array}$ & $\operatorname{Iran}(\mathbf{P})$ & $\operatorname{Jordan}(\mathbf{P})$ \\
\hline \multirow[t]{2}{*}{1978} & Ecuador(P) & Egypt(P) & Gibraltar(P) & Haiti(P) & $\operatorname{Iraq}(P)$ \\
\hline & $\begin{array}{l}\text { Mozambique(P) } \\
\text { St. Kitts Nevis(P) }\end{array}$ & $\begin{array}{l}\text { Oman(P) } \\
\text { Tanzania(P) }\end{array}$ & Papua N. Guinea(P) & Samoa(P) & Sierra Leone $(P)$ \\
\hline \multirow[t]{3}{*}{1979} & Algeria(P) & Angola $(\mathrm{P})$ & China(P) & Congo(P) & Djibouti(P) \\
\hline & El Salvador(P) & Mauritius(P) & Neth. Antilles (P) & Nicaragua(P) & Pakistan(P) \\
\hline & Qatar $(P)$ & Sri Lanka(P) & Syria(P) & & \\
\hline 1980 & $\begin{array}{l}\text { Guatemala(P) } \\
\text { Uruguay }(P)\end{array}$ & Liberia(P) & Libya(P) & Madagascar $(P)$ & Sudan(P) \\
\hline \multirow[t]{3}{*}{1981} & Brunei/Bhutan(P) & Bangladesh(P) & Belize(P) & Costa Rica(P) & Dem. Rep. Congo(P) \\
\hline & Dominican Rep(P) & Fiji(P) & Guadeloupe(P) & Seychelles $(P)$ & $\operatorname{Tog}(P)$ \\
\hline & Tunisia(P) & Turkey $(\mathrm{P})$ & Venezuela $(\mathbf{P})$ & & \\
\hline 1982 & Gambia(P) & Kiribati(P) & Mauritania(P) & St. Helena (P) & \\
\hline 1983 & Bermuda(P) & Ethiopia(P) & Guinea(P) & Malta(P) & Myanmar $(\mathbf{P})$ \\
\hline
\end{tabular}

Figure 10.1: Timeline of Containerization, reproduced from Bernhofen et al. (2016) 
11 Appendix C: Regression Tables for Main Results 


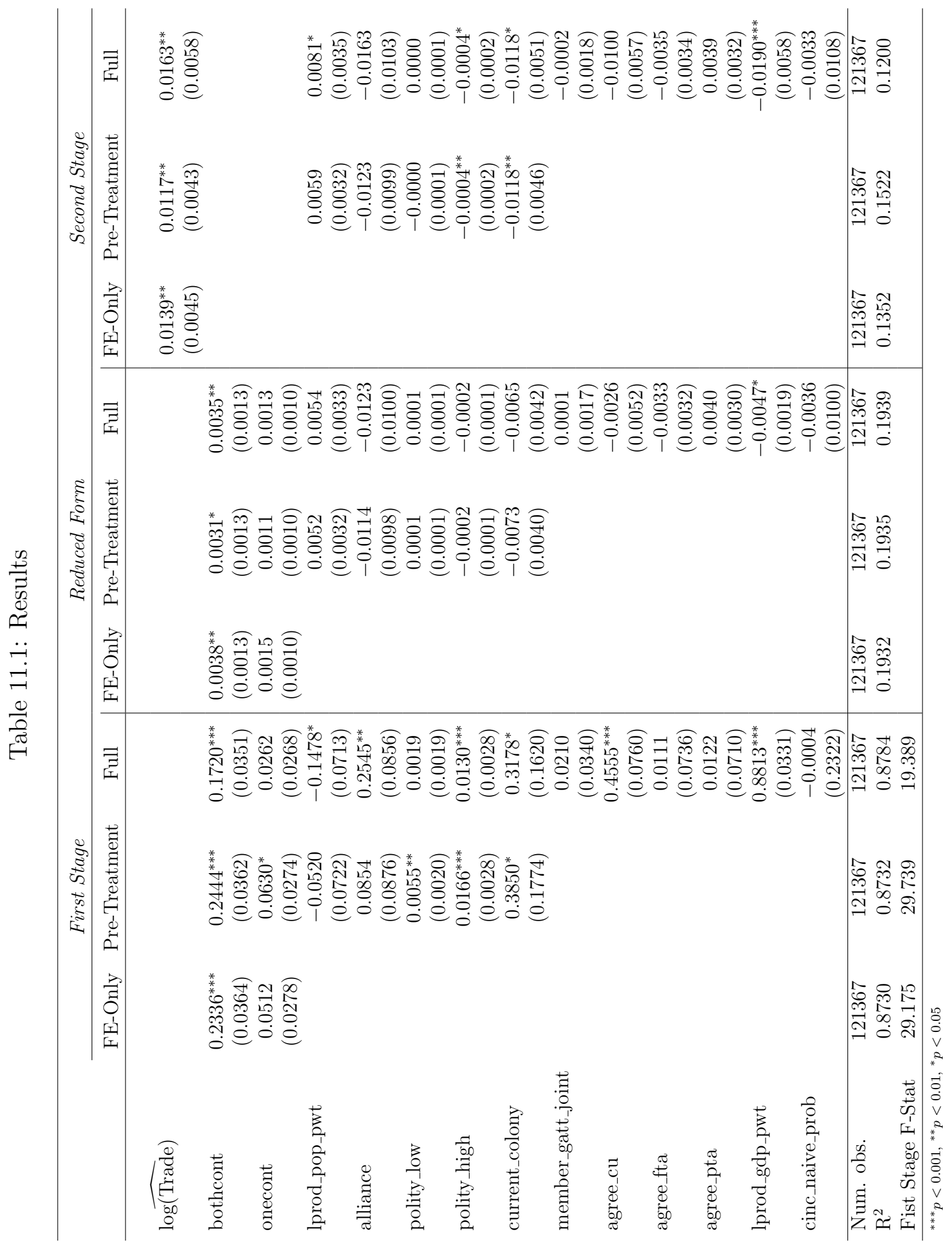




\section{Appendix D: Robustness}

Table 12.1: First Stage IHS Transformation with Linear Second Stage

\begin{tabular}{|c|c|c|c|}
\hline & First Stage & Reduced Form & Second Stage \\
\hline IHS(Trade) & & & $\begin{array}{l}0.0029^{*} \\
(0.0014)\end{array}$ \\
\hline onecont & $\begin{array}{c}-0.1251^{* * *} \\
(0.0117)\end{array}$ & $\begin{array}{c}0.0004 \\
(0.0006)\end{array}$ & \\
\hline bothcont & $\begin{array}{c}0.2562^{* * *} \\
(0.0189)\end{array}$ & $\begin{array}{c}0.0016 \\
(0.0009)\end{array}$ & \\
\hline member_gatt_joint & $\begin{array}{c}0.0175 \\
(0.0215)\end{array}$ & $\begin{array}{c}0.0004 \\
(0.0012)\end{array}$ & $\begin{array}{c}0.0003 \\
(0.0013)\end{array}$ \\
\hline agree_cu & $\begin{array}{c}0.6640^{* * *} \\
(0.0801)\end{array}$ & $\begin{array}{l}-0.0017 \\
(0.0050)\end{array}$ & $\begin{array}{l}-0.0037 \\
(0.0048)\end{array}$ \\
\hline agree_fta & $\begin{array}{c}-0.1871^{* * *} \\
(0.0553)\end{array}$ & $\begin{array}{l}-0.0040 \\
(0.0034)\end{array}$ & $\begin{array}{l}-0.0035 \\
(0.0031)\end{array}$ \\
\hline agree_pta & $\begin{array}{c}0.2139^{* * *} \\
(0.0534)\end{array}$ & $\begin{array}{c}0.0041 \\
(0.0033)\end{array}$ & $\begin{array}{c}0.0035 \\
(0.0031)\end{array}$ \\
\hline lprod_gdp_pwt & $\begin{array}{c}0.5170^{* * *} \\
(0.0209)\end{array}$ & $\begin{array}{c}-0.0026^{*} \\
(0.0012)\end{array}$ & $\begin{array}{c}-0.0041^{* *} \\
(0.0015)\end{array}$ \\
\hline lprod_pop_pwt & $\begin{array}{c}-0.8400^{* * *} \\
(0.0477)\end{array}$ & $\begin{array}{c}0.0023 \\
(0.0021)\end{array}$ & $\begin{array}{c}0.0051 \\
(0.0027)\end{array}$ \\
\hline cinc_naive_prob & $\begin{array}{c}0.0454 \\
(0.1506)\end{array}$ & $\begin{array}{l}-0.0035 \\
(0.0072)\end{array}$ & $\begin{array}{l}-0.0034 \\
(0.0068)\end{array}$ \\
\hline alliance & $\begin{array}{c}0.0338 \\
(0.0517)\end{array}$ & $\begin{array}{l}-0.0078 \\
(0.0073)\end{array}$ & $\begin{array}{l}-0.0078 \\
(0.0073)\end{array}$ \\
\hline polity_low & $\begin{array}{c}0.0061^{* * *} \\
(0.0014)\end{array}$ & $\begin{array}{c}0.0000 \\
(0.0001)\end{array}$ & $\begin{array}{c}0.0000 \\
(0.0001)\end{array}$ \\
\hline polity_high & $\begin{array}{c}0.0063^{* * *} \\
(0.0015)\end{array}$ & $\begin{array}{l}-0.0001 \\
(0.0001)\end{array}$ & $\begin{array}{l}-0.0001 \\
(0.0001)\end{array}$ \\
\hline current_colony & $\begin{array}{l}-0.1285 \\
(0.1710) \\
\end{array}$ & $\begin{array}{l}-0.0066 \\
(0.0037) \\
\end{array}$ & $\begin{array}{c}-0.0062^{*} \\
(0.0030)\end{array}$ \\
\hline $\begin{array}{l}\text { Num. obs. } \\
\mathrm{R}^{2}\end{array}$ & $\begin{array}{l}175212 \\
0.9053\end{array}$ & $\begin{array}{l}175212 \\
0.2282\end{array}$ & $\begin{array}{l}175212 \\
0.2268\end{array}$ \\
\hline
\end{tabular}


Table 12.2: First Stage Log with Second Stage Probit

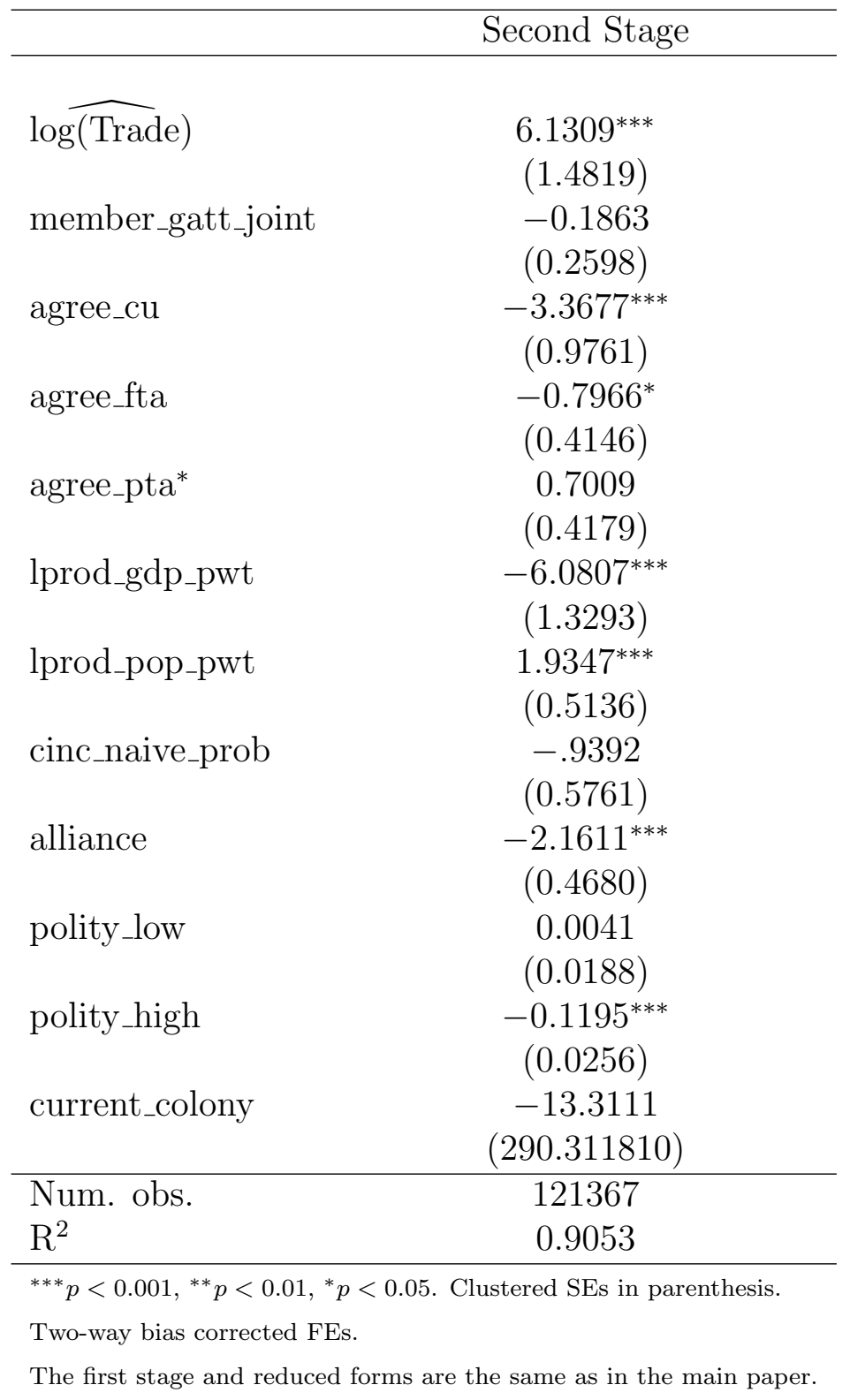


Table 12.3: With Fully Imputed Trade, GDP, and Population

\begin{tabular}{|c|c|c|}
\hline & Logged First Stage & IHS First Stage \\
\hline$\widehat{\log (\text { Trade })}$ & $\begin{array}{c}0.0098 \\
(0.0063)\end{array}$ & \\
\hline IHS(Trade) & & $\begin{array}{c}0.0020 \\
(0.0016)\end{array}$ \\
\hline member_gatt_joint & $\begin{array}{c}-0.0011 \\
(0.0019)\end{array}$ & $\begin{array}{c}0.0002 \\
(0.0010)\end{array}$ \\
\hline agree_cu & $\begin{array}{l}-0.0039 \\
(0.0057)\end{array}$ & $\begin{array}{l}-0.0026 \\
(0.0051)\end{array}$ \\
\hline agree_fta & $\begin{array}{l}-0.0019 \\
(0.0030)\end{array}$ & $\begin{array}{l}-0.0030 \\
(0.0029)\end{array}$ \\
\hline agree_pta & $\begin{array}{c}0.0022 \\
(0.0029)\end{array}$ & $\begin{array}{c}0.0028 \\
(0.0029)\end{array}$ \\
\hline lprod_gdp_gled & $\begin{array}{r}-0.0115^{*} \\
(0.0052)\end{array}$ & $\begin{array}{c}-0.0034^{* *} \\
(0.0012)\end{array}$ \\
\hline lprod_pop_gled & $\begin{array}{l}0.0168^{* *} \\
(0.0052)\end{array}$ & $\begin{array}{l}0.0066^{* *} \\
(0.0025)\end{array}$ \\
\hline cinc_naive_prob & $\begin{array}{c}0.0024 \\
(0.0089)\end{array}$ & $\begin{array}{r}-0.0032 \\
(0.0048)\end{array}$ \\
\hline alliance & $\begin{array}{c}-0.0018 \\
(0.0083)\end{array}$ & $\begin{array}{c}0.0012 \\
(0.0058)\end{array}$ \\
\hline jointd & $\begin{array}{l}-0.0012 \\
(0.0012)\end{array}$ & $\begin{array}{l}-0.0007 \\
(0.0010)\end{array}$ \\
\hline current_colony & $\begin{array}{c}0.0200 \\
(0.0287)\end{array}$ & $\begin{array}{c}0.0210 \\
(0.0254)\end{array}$ \\
\hline $\begin{array}{l}\text { Num. obs. } \\
\mathrm{R}^{2}\end{array}$ & $\begin{array}{l}172596 \\
0.2168\end{array}$ & $\begin{array}{l}301693 \\
0.2442\end{array}$ \\
\hline
\end{tabular}


Table 12.4: Extant Trade Data with Imputed GDP, and Population

\begin{tabular}{|c|c|c|}
\hline & Logged First Stage & IHS First Stage \\
\hline$\widehat{\log (\text { Trade })}$ & $\begin{array}{c}0.0139 \\
(0.0073)\end{array}$ & \\
\hline IHS(Trade) & & $\begin{array}{c}0.0032 \\
(0.0018)\end{array}$ \\
\hline member_gatt_joint & $\begin{array}{c}-0.0014 \\
(0.0020)\end{array}$ & $\begin{array}{c}0.0002 \\
(0.0011)\end{array}$ \\
\hline agree_cu & $\begin{array}{c}-0.0034 \\
(0.0058)\end{array}$ & $\begin{array}{l}-0.0026 \\
(0.0052)\end{array}$ \\
\hline agree_fta & $\begin{array}{c}-0.0011 \\
(0.0031)\end{array}$ & $\begin{array}{c}-0.0029 \\
(0.0030)\end{array}$ \\
\hline agree_pta & $\begin{array}{c}0.0013 \\
(0.0030)\end{array}$ & $\begin{array}{c}0.0024 \\
(0.0029)\end{array}$ \\
\hline lprod_gdp_gled & $\begin{array}{c}-0.0173^{*} \\
(0.0073)\end{array}$ & $\begin{array}{c}-0.0046^{* *} \\
(0.0014)\end{array}$ \\
\hline lprod_pop_gled & $\begin{array}{l}0.0215^{* *} \\
(0.0068)\end{array}$ & $\begin{array}{l}0.0092^{* *} \\
(0.0031)\end{array}$ \\
\hline cinc_naive_prob & $\begin{array}{c}0.0051 \\
(0.0101)\end{array}$ & $\begin{array}{l}-0.0021 \\
(0.0057)\end{array}$ \\
\hline alliance & $\begin{array}{c}-0.0041 \\
(0.0089)\end{array}$ & $\begin{array}{c}-0.0004 \\
(0.0059)\end{array}$ \\
\hline jointd & $\begin{array}{l}-0.0016 \\
(0.0013)\end{array}$ & $\begin{array}{l}-0.0008 \\
(0.0010)\end{array}$ \\
\hline current_colony & $\begin{array}{c}0.0188 \\
(0.0301)\end{array}$ & $\begin{array}{c}0.0219 \\
(0.0266)\end{array}$ \\
\hline $\begin{array}{l}\text { Num. obs. } \\
R^{2}\end{array}$ & $\begin{array}{l}166326 \\
0.1865\end{array}$ & $\begin{array}{c}255045 \\
0.2480\end{array}$ \\
\hline
\end{tabular}

